\title{
Importance of the Indian Ocean for simulating rainfall anomalies over eastern and southern Africa
}

\author{
Lisa Goddard and Nicholas E. Graham \\ International Research Institute for Climate Prediction, Experimental Forecast Division, Scripps Institution of \\ Oceanography, La Jolla, California
}

\begin{abstract}
The relative contributions of the Indian Ocean and Pacific Ocean sea surface temperatures (SSTs) to the rainfall variability over eastern central, and southern Africa during the austral spring-summer are examined. The variability of African rainfall is statistically related to both oceans, but the variability in the two oceans is also related. To separate the effects of the Indian and Pacific Oceans, a suite of numerical model simulations is presented: GOGA, the atmosphere is forced by observed SSTs globally; IOGA, the atmosphere is forced by observed SSTs only in the Indian Ocean basin; and POGA, the atmosphere is forced by observed SSTs only in the tropical Pacific basin. While the SST variability of the tropical Pacific exerts some influence over the African region, it is the atmospheric response to the Indian Ocean variability that is essential for simulating the correct rainfall response over eastern, central, and southern Africa. Analyses of the dynamical response(s) seen in the numerical experiments and in the observations indicate that the Pacific and Indian Oceans have a competing influence over the Indian Ocean/African region. This competition is related to the influence of the two oceans on the Walker circulation and the consequences of that variability on low-level fluxes of moisture over central and southern Africa. Finally, given the high correlation found between SST variability in the Indian and Pacific Oceans with the Pacific leading by $\sim 3$ months, we speculate on an approach to long-lead dynamical climate prediction over central-east and southern Africa.
\end{abstract}

\section{Introduction}

In 1997-1998 austral spring and summer, during one of the strongest El Niño events of the century and concurrent strongest warmings of the century in the Indian Ocean [Webster et al., 1999], record precipitation fell over eastern Africa [Halpern and Bell, 1998]. Guilty by association, El Niño has been blamed for that record rainfall and subsequent devastation. However, numerical predictions of the atmospheric variability driven only with the El Niño-related sea surface temperature changes in the tropical Pacific did not simulate the heavy rains over East Africa. On the other hand, when the atmospheric models were forced at the lower boundary with global sea surface temperature (SST) anomalies, the heavy East African rains were produced. Does El Niño (and its counterpart, La Niña) affect climate variability over Africa directly or indirectly? What is the role of SST variability in the other ocean basins? In this paper we look specifically at the role of the Indian Ocean compared to that of the Pacific Ocean as well as their combined effect.

From September to February the climatological evolution of rainfall in eastern and southern Africa is dominated by the southward migration of the Intertropical Convergence Zone (ITCZ) axis from its late boreal summer position north of the equator extending across southern portions of Ethiopia and Sudan. This migration takes the ITCZ first through Kenya, the lake countries, and northern Tanzania during October and November; these are known as the short rains. The ITCZ then

Copyright 1999 by the American Geophysical Union.

Paper number 1999JD900326. 0148-0227/99/1999JD900326\$09.00 moves rapidly southward across southern Tanzania into Zambia, Zimbabwe, Malawi, and central Mozambique, from December to February, this latter representing the principal rain season over southern Africa. It has long been noted that interannual variability in rainfall over central-east and southern Africa during the October-February season correlates strongly with the sea surface temperature (SST) changes in the tropical Pacific associated with the El Niño-Southern Oscillation (ENSO) phenomenon [e.g., Stoeckenius, 1981; Nicholson and Entekhabi, 1987; Ropelewski and Halpert, 1987; Ogallo, 1988; Lindesay, 1988; van Heerden et al., 1988; Janowiak, 1988; Ropelewski and Halpert, 1989; Lindesay and Vogel, 1990; Hastenrath et al., 1993] and also with variability of Indian Ocean SSTs [Ogallo et al., 1989; Pathack, 1993; Landman, 1995; Jury et al., 1996; Rocha and Simmonds, 1997a; Landman and Mason, 1999].

The dominant pattern of interannual variability in the austral spring and summer rainfall represents a regional shift of the climatological rainfall pattern, with anomalies of opposing sign in central-east and southern Africa [cf. Mutai et al., 1998] (i.e., on either side of the ITCZ climatological position). Plate 1 shows the leading empirical orthogonal function (EOF) of observed November-January (NDJ) rainfall (see section 2) over central and southern Africa for the period 1950-1995. The spatial pattern (Plate 1a), expressed as correlations between the NDJ rainfall and the EOF temporal function, is a dipole, with positive correlations covering all of eastern Africa between $\sim 20^{\circ} \mathrm{N}$ and $20^{\circ} \mathrm{S}$ and negative correlations poleward of $20^{\circ} \mathrm{S}$. Correlations reach 0.6 to 0.8 in the northern center of the dipole, located over southern Kenya, Tanzania, Malawi, and northern Zambia, and -0.4 to -0.6 in the southern center in eastern Botswana, southern Zimbabwe, and northern South 

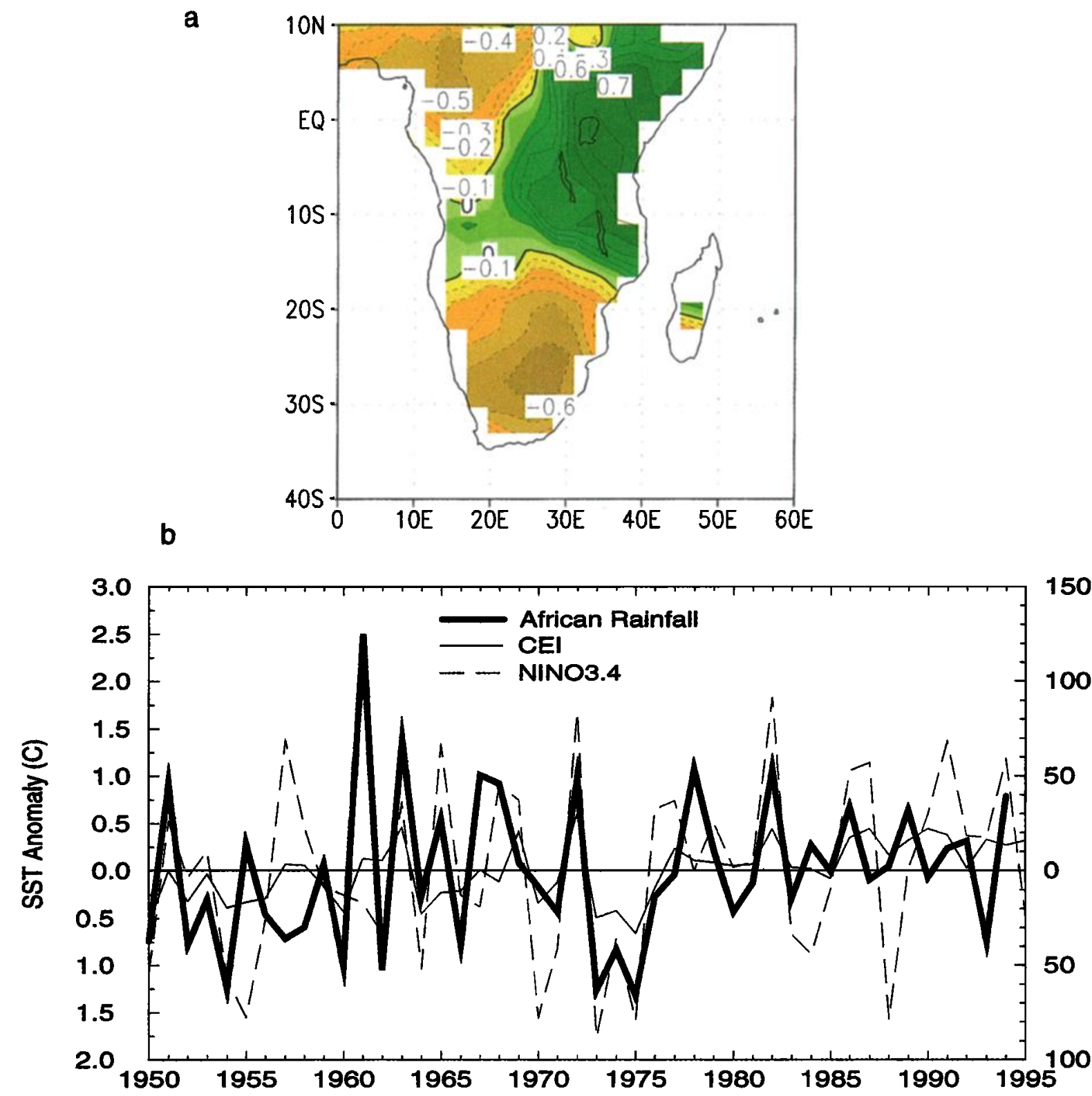

Plate 1. (a) First empirical orthogonal function (EOF) of observed rainfall anomalies for NovemberDecember-January 1950-1995, plotted as correlations between the rainfall anomalies and the EOF temporal function. (b) Time series for amplitude of EOF (shown in Plate 1a) (thick solid line), amplitude on right axis. Also plotted are time series of sea surface temperature (SST) indices for the Pacific Ocean, NINO3.4 $\left(5^{\circ} \mathrm{S}-5^{\circ} \mathrm{N} ; 170^{\circ} \mathrm{W}-110^{\circ} \mathrm{W}\right)$ (dashed line), and the Indian Ocean, CEI (central equatorial Indian index) $\left(15^{\circ} \mathrm{S}-0\right.$; $50^{\circ} \mathrm{E}-80^{\circ} \mathrm{E}$ ) (thin solid line).

Africa. The temporal function of the EOF is shown in Plate $1 \mathrm{~b}$, along with indices of SST variability (from the data of Smith et al. [1996]), in the tropical Pacific (NINO3.4: $5^{\circ} \mathrm{S}-5^{\circ} \mathrm{N}, 170^{\circ} \mathrm{W}-$ $110^{\circ} \mathrm{W}$ ) and Indian Oceans (the central equatorial Indian index (CEI): $0-15^{\circ} \mathrm{S}, 50^{\circ} \mathrm{E}$ to $80^{\circ} \mathrm{E}$ ). Apparent in the figure are associations between the African rainfall and the SST variability in both the Pacific and the Indian Oceans, including the 3-5 year fluctuations associated with ENSO (e.g., 1972-1973, 1977-1978, 1982-1983), and other peaks apparently unrelated to ENSO, notably that associated with the major Indian Ocean event in 1961 [Flohn, 1987; Cadet, 1985] and a smaller episode in 1967 . Generally more muted variability is depicted following the late 1970 s, behavior that has been linked by Landman and
Mason [1999] to a weakening of the southern center of the dipole, possibly in response to upward trends in Indian Ocean SSTs. Also apparent in Plate 1b, and previously noted by others [e.g., Pan and Oort, 1983], is the association between SST variability in the western and central tropical Indian Ocean with that in the tropical Pacific. The character of this association is brought out more clearly in Figure 1, which shows the lagged autocorrelation and cross correlation between the NINO3.4 and the CEI indices. Note that the two indices have very similar autocorrelation functions. The cross-correlation function shows that the tropical Pacific and Indian Ocean SST changes are well correlated $(r=0.75)$, with the former leading by 3 months. 


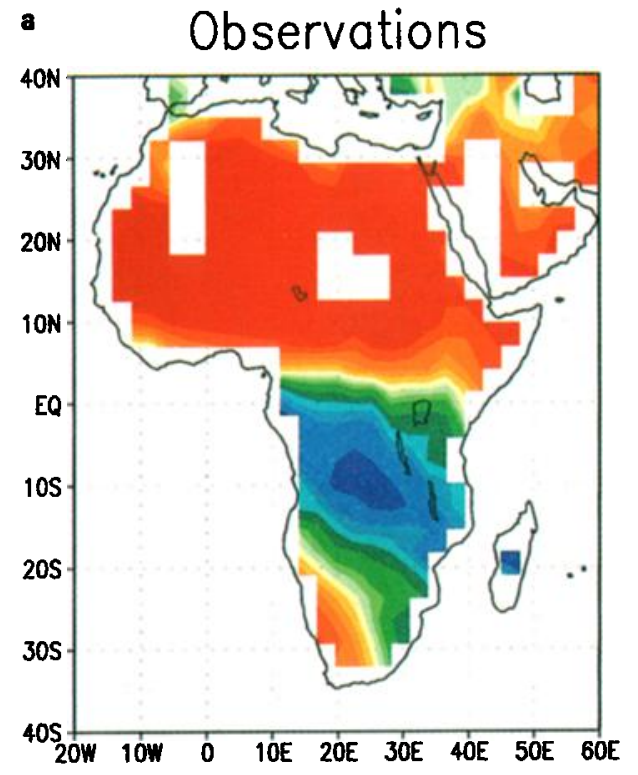

b

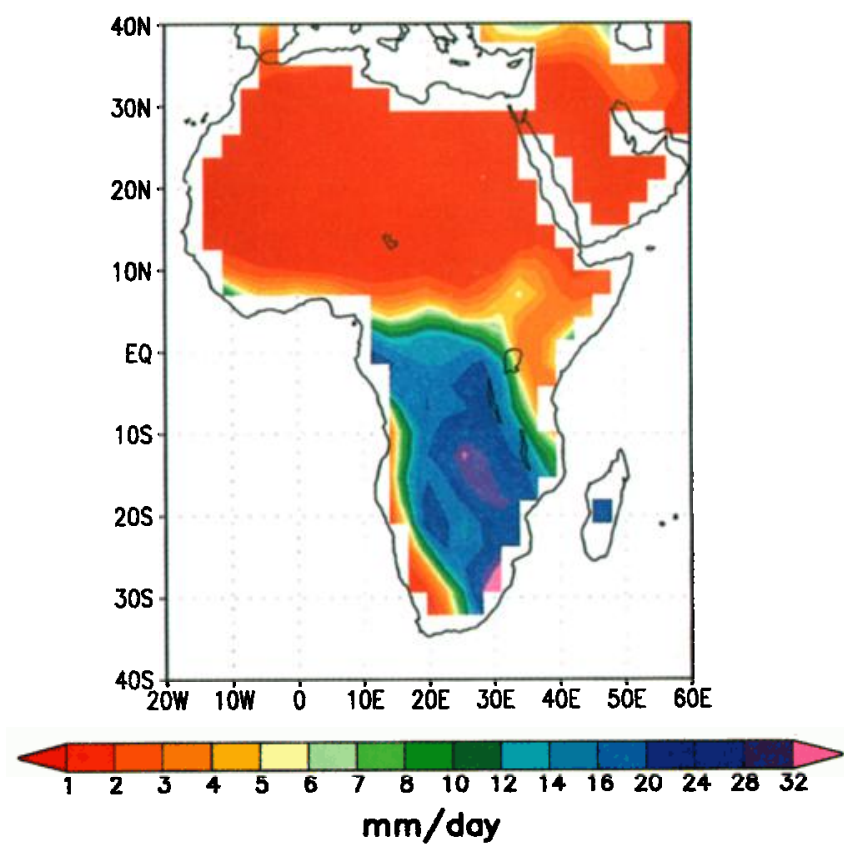

Plate 2. Climatological rainfall rate $\left(\mathrm{mm} \mathrm{d}^{-1}\right)$ for November-December-January season from (a) observations and (b) as simulated by the ECHAM3 AGCM.

These relationships raise an important question concerning the associations among ENSO, the Indian Ocean variability, and the characteristic dipole pattern of anomalous rainfall over central-east/southern Africa. Does ENSO force the climate variability over Africa directly, by influencing the global atmospheric circulation, or indirectly, by inducing changes in the Indian Ocean temperatures, which then affect the local atmospheric circulation and produce the changes in regional precipitation? This question is difficult to answer using observational data alone because important aspects of SST variability in the tropical Indian and Pacific Oceans are coincident. We

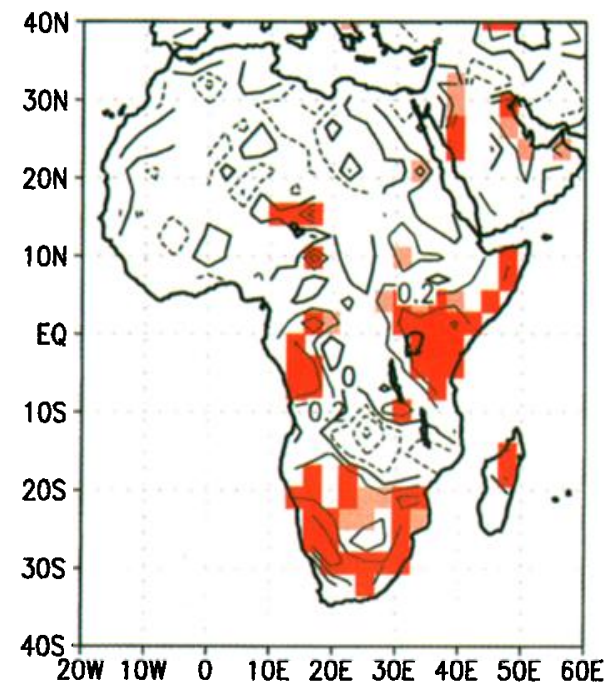

Plate 3. Temporal correlations between observed and simulated rainfall anomalies for November-December-January 1970-1992. Contour interval is 0.2. Light shading indicates correlations significant at the $10 \%$ level; dark shading indicates significance at the 5\% level (as determined by Monte Carlo tests).

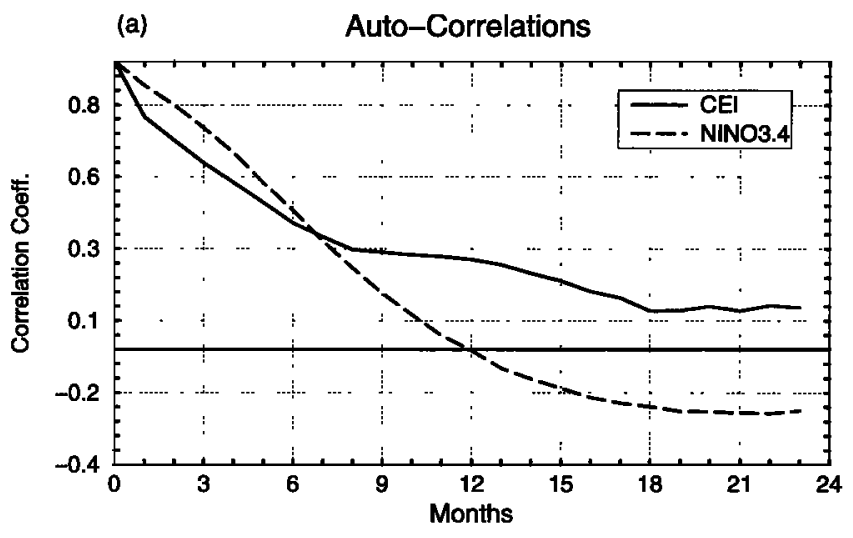

(b)

Time-Lag Correlation

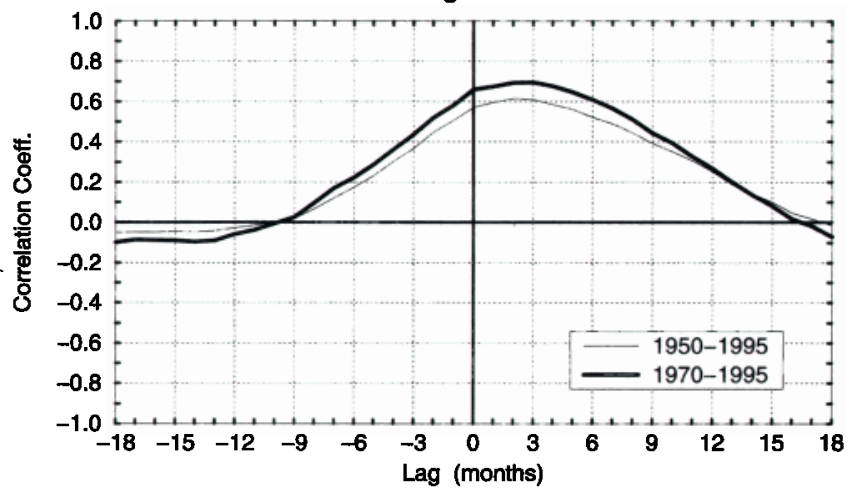

Figure 1. (a) Autocorrelations of SST indices: NINO3.4 $\left(5^{\circ} \mathrm{S}-5^{\circ} \mathrm{N} ; 170^{\circ} \mathrm{W}-110^{\circ} \mathrm{W}\right)$ (dashed line); CEI $\left(15^{\circ} \mathrm{S}-0 ; 50^{\circ} \mathrm{E}-\right.$ $80^{\circ} \mathrm{E}$ ) (solid line). (b) Time-lag correlations between the SST indices of (a) for the 1950-1995 period (thin solid line) and also 1970-1995 (thick solid line). NINO3.4 leads CEI for positive lag values. 
a OBSERVATIONS

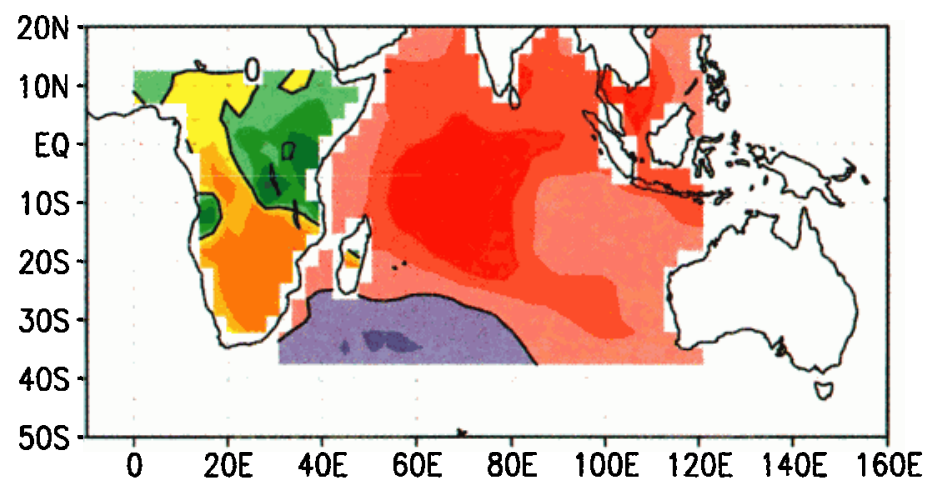

b

GOGA

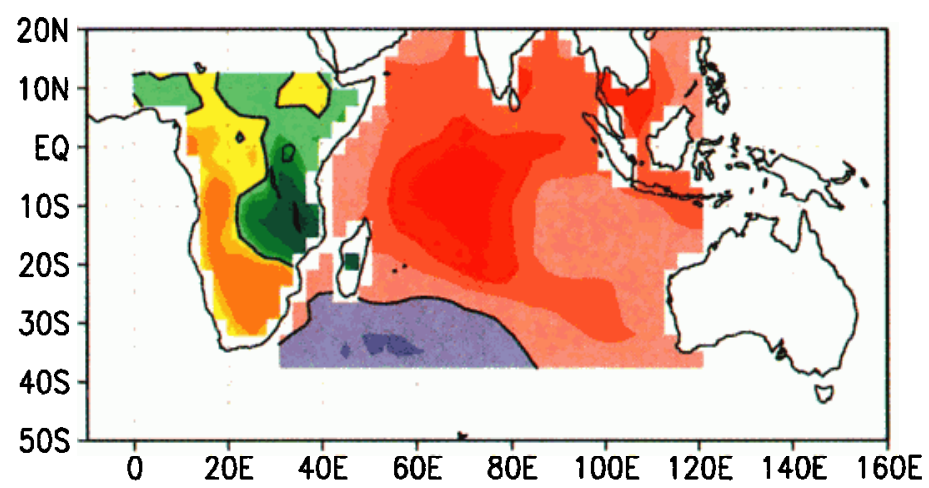

c

IOGA

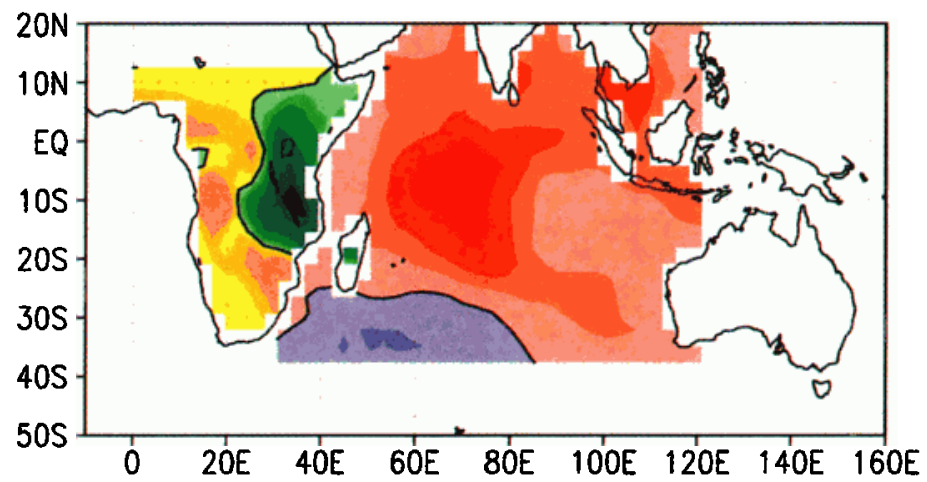

$\mathrm{cm} /$ month
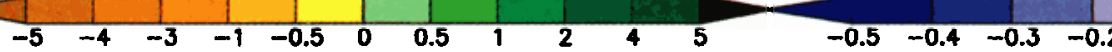

deg. $\mathrm{C}$

Plate 4. Dominant patterns of precipitation variability over Africa and SST variability over the Indian Ocean for November-December-January of 1970-1992. In all cases the SST is represented by the homogeneous response map on the basis of observed data. The precipitation pattern is based on (a) observations showing the heterogeneous response map; (b) GOGA experiment showing the pseudo-heterogeneous response map; and (c) IOGA experiment showing the pseudo-heterogeneous response map.

have attempted to answer the question using a suite of experiments with an atmospheric general circulation model (AGCM) that qualitatively reproduces the observed precipitation climatology and seasonal-to-interannual variability over eastern and southern Africa during the period under analysis. The observed data and the results of these experiments are analyzed with respect to variability in eastern and southern African rainfall, changes in moisture transport over Africa and the Indian Ocean, and alterations in vertical motion and divergent component of the zonal motion along the equator (i.e., variability in the Walker-type circulation cells). The analyses focus on the November-January period which comprises im- 
a

\section{OBSERVATIONS}

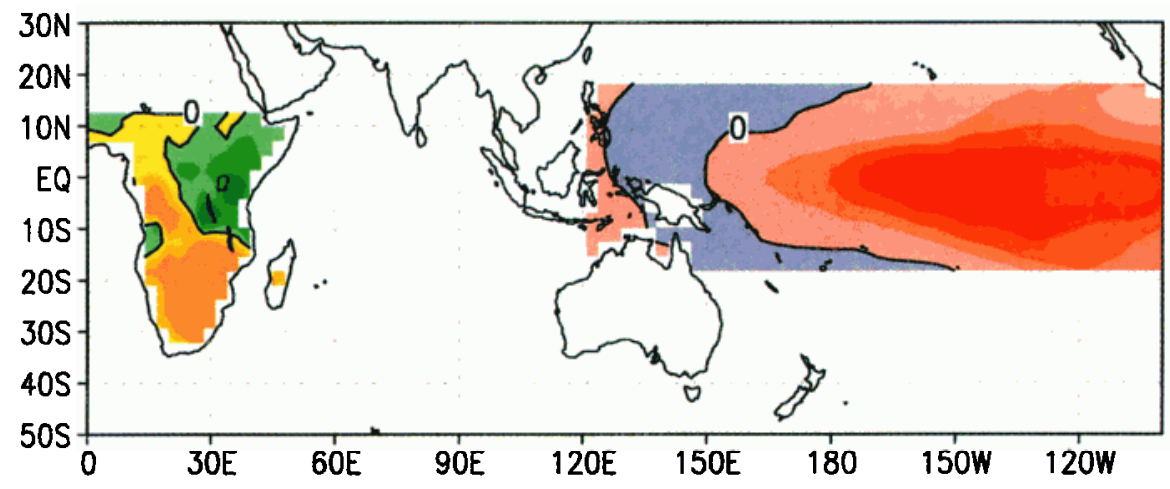

b

GOGA

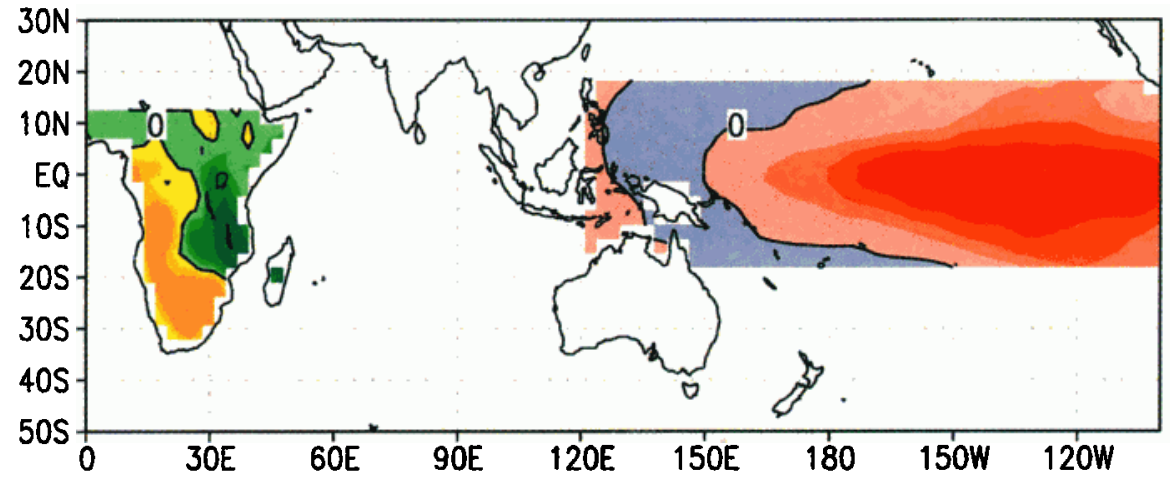

C

POGA

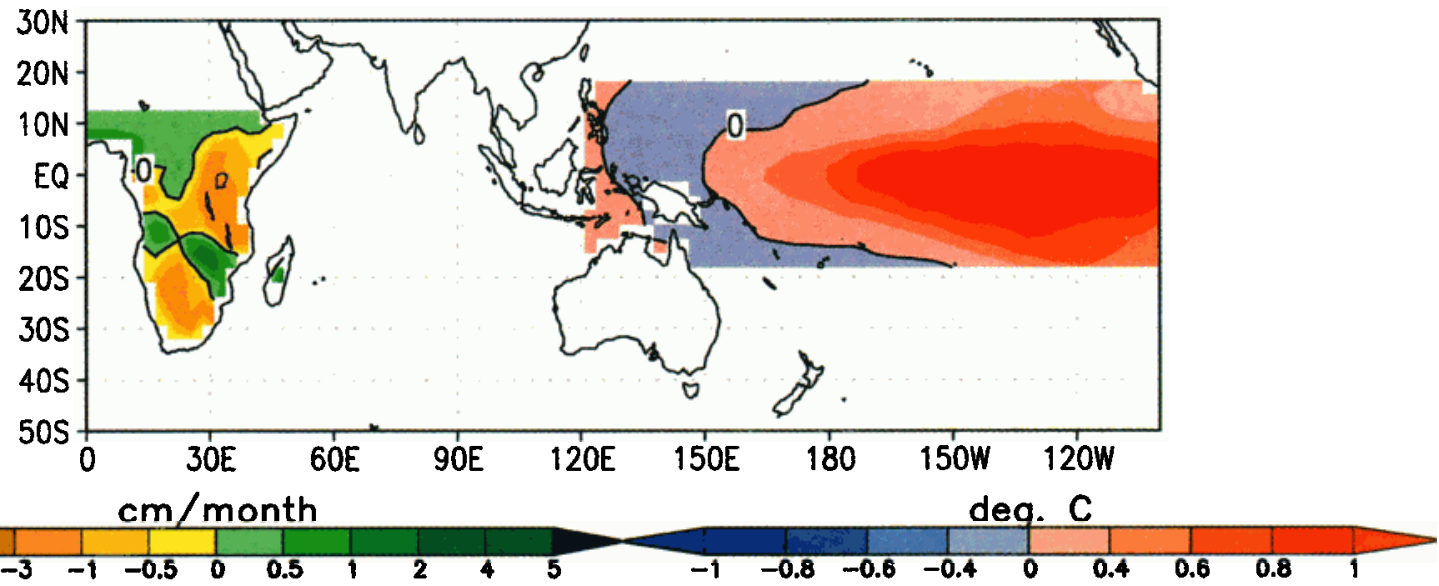

Plate 5. Similar to Plate 4, here relating precipitation to Pacific SST variability. (a) observations, (b) GOGA experiment, and (c) POGA experiment.

portant parts of the rainfall season in both regions (climatologically, slightly earlier and later periods are relatively more important in the central-east and southern Africa, respectively).

Our findings provide new insights into the genesis of regional climate changes over Africa and the impact of Indian Ocean SST variability on global tropical circulation. They also have important practical implications for seasonal-tointerannual climate forecasting, in that they emphasize the requirement for accurate predictions of Indian Ocean SSTs to obtain useful predictions of rainfall in southern and eastern Africa (and by extension, for other regions). Present systems for seasonal-to-interannual prediction, whether they be onetiered (i.e., predicting the SSTs and climate anomalies in one step with coupled ocean and atmospheric models [e.g., Stockdale et al., 1998]) or two-tiered (predicting SSTs in one step, and the atmospheric response using an AGCM in another 



Plate 6. Anomalous NDJ moisture fluxes at 850 mbar (arrows) in $\mathrm{m} \mathrm{s}^{-1} \mathrm{~g} \mathrm{~kg}^{-1}$ and associated moisture convergence (shading) $\mathrm{g} \mathrm{kg}^{-1} \mathrm{~s}^{-1}$ from the GOGA experiment for (a) 1975-1976, a "cold year," negative manifestation of centraleastern/southern Africa rainfall dipole; and (b) 1982-1983, a "warm" year, positive manifestation of dipole.

[e.g., Bengtsson et al., 1993; Graham, 1987]), commonly (and naturally) focus on the quality of the SST predictions in the tropical Pacific as the basis for successful atmospheric predictions. Our findings, like the idealized experiments regrading the role of Atlantic SSTs on Brazilian precipitation [Moura and Shukla, 1981], emphasize the requirement for accurate SST predictions in other oceans as well.

The presentation is organized as described below. Following this Introduction, section 2 describes the observational data, the atmospheric model and model data, experiment design, and the analysis methods. Section 3 presents the results, and section 4 provides a discussion and the conclusions.

\section{Data and Methods}

\subsection{Observed Data}

2.1.1. SST. The observed SST data used in this work come from the National Centers for Environmental Prediction (NCEP) statistically reconstructed SST data set [Smith et al., 1996]. These SST data are available for the global oceans on a $2.5^{\circ}$ latitude-longitude grid. The SST data serve as the lowerboundary condition forcing for the AGCM and were linearly interpolated to the $\sim 2.8^{\circ}$ model grid. The SST data are also used in the statistical analyses relating the observed and sim-

Plate 7. Similar to Plate 6 but for the IOGA experiment. Now showing vertically integrated moisture fluxes and flux convergences.

ulated changes in rainfall to the changes in SSTs, and for these purposes, anomalies were expressed as departures from the mean annual cycle for the 1970-1992 analysis period.

2.1.2. Precipitation. The precipitation data come from the Global Climatological Historical Network (GHCN) precipitation data set described by Eischeid et al. [1991] [cf. Vose et al., 1992]. This data set is based on rain gage measurements, which were subjected to strict quality control procedures. These data, originally supplied on on a $5^{\circ}$ latitude-longitude grid, were linearly interpolated onto the $2.8^{\circ}$ model grid, and anomalies referenced to the 1970-1992 period, for analysis purposes.

2.1.3. Moisture flux and vertical velocities. Observed 850 $\mathrm{hPa}$ moisture flux and horizontal winds, from which the vertical velocity is deduced, come from the NCEP/National Center for Atmospheric Research (NCAR) reanalysis [Kalnay et al., 1996]. The decision to use $850 \mathrm{hPa}$ fluxes, rather than vertically integrated moisture flux data, was based on the fact that only the $850 \mathrm{hPa}$ were available for comparison from the GOGA simulation.

\subsection{AGCM, Experimental Design, and Model Data}

2.2.1. AGCM. The AGCM used in this study is the socalled ECHAM3.2 AGCM, a version of the climate model evolving at the Max Planck Institute for Meteorology at the University of Hamburg. For the experiments presented here, 
the hybrid sigma coordinate, spectral transform model was configured at triangular 42 (T42) spectral truncation, giving a spatial resolution of about $2.8^{\circ}$ latitude-longitude, with 19 vertical layers. The convection parameterization is from Tiedtke [1989], which uses a mass flux scheme for deep, shallow, and midlevel convection. The model includes prognostic clouds and prognostic cloud water and uses the radiation scheme of Eickerling [1989]. The land surface parameterizations include a snow cover model, a catchment-based soil-moisture/runoff treatment, and vegetative effects. Description of the numerics and physical parameterizations are available from the Deutsches Klimarechenzentrum (DKRZ) [1992]. The ECHAM3 AGCM was selected for this study because of the ability of this model to simulate the climate variability over southern and eastern Africa during the austral spring-summer rainy season(s), October-February. As will be demonstrated later, correlations between seasonal observed and simulated rainfall exceed 0.4-0.5 over large areas of eastern and southern Africa during this period, and the two show similar and temporally coherent dominant patterns of spatial variability.

2.2.2. Experiment design. Three sets of ensemble AGCM experiments were performed for this study, each covering the period 1970-1992. In one ensemble of simulations (GOGA: Global Ocean-Global Atmosphere), observed timevarying SSTs were prescribed globally. In a second ensemble experiment (IOGA: Indian Ocean-Global Atmosphere), time-varying SSTs were prescribed only in the Indian Ocean, meridionally from $40^{\circ} \mathrm{S}$ to the Asian coast and zonally from the African coast to $120^{\circ} \mathrm{E}$. The climatological annual cycle of SSTs were prescribed elsewhere. In the third ensemble experiment (POGA: Pacific Ocean-Global Atmosphere), timevarying SSTs were prescribed only in the Pacific Ocean between $20^{\circ} \mathrm{N}$ and $20^{\circ} \mathrm{S}$, and from $120^{\circ} \mathrm{E}$ to the coast of the Americas, with climatology elsewhere.

Each of the three AGCM experiments was composed of an ensemble of five integrations, each ensemble member using identical SSTs and different atmospheric initial conditions. These initial conditions were obtained by starting the model on December 1, 1969 (using a restart file from another set of simulations), integrating forward for 1 day, writing a second restart file, and continuing the simulation. This second restart file, altered to show a start date of December 1, 1969, then served as the initial condition for a second simulation from which a third restart file was similarly obtained. This process was repeated for the fourth and fifth ensemble members. Although this technique does not provide truly independent restart conditions, for extended simulations such as these, any systematic effects are unimportant. For the analyses described in this paper, the results from the five ensemble members from each experiment have been averaged together, the resulting ensemble mean providing an approximation of the reproducible response of the model to the prescribed SSTs.

2.2.3. Simulated moisture fluxes and vertical velocities. For a variety of reasons, moisture flux data from the GOGA simulations were saved only for a few levels and, unfortunately, the vertical integrals were not retained. Comparison of vertically integrated moisture fluxes and those at $850 \mathrm{mbar}$, available from the NCEP/NCAR reanalysis, confirms that the lowlevel moisture fields are indeed representative of the total fields in our region of interest. Thus the data from $850 \mathrm{hPa}$ are used here as most representative of the behavior of the vertically integrated quantity. For the IOGA and POGA simulations, vertically integrated moisture data were saved (but that
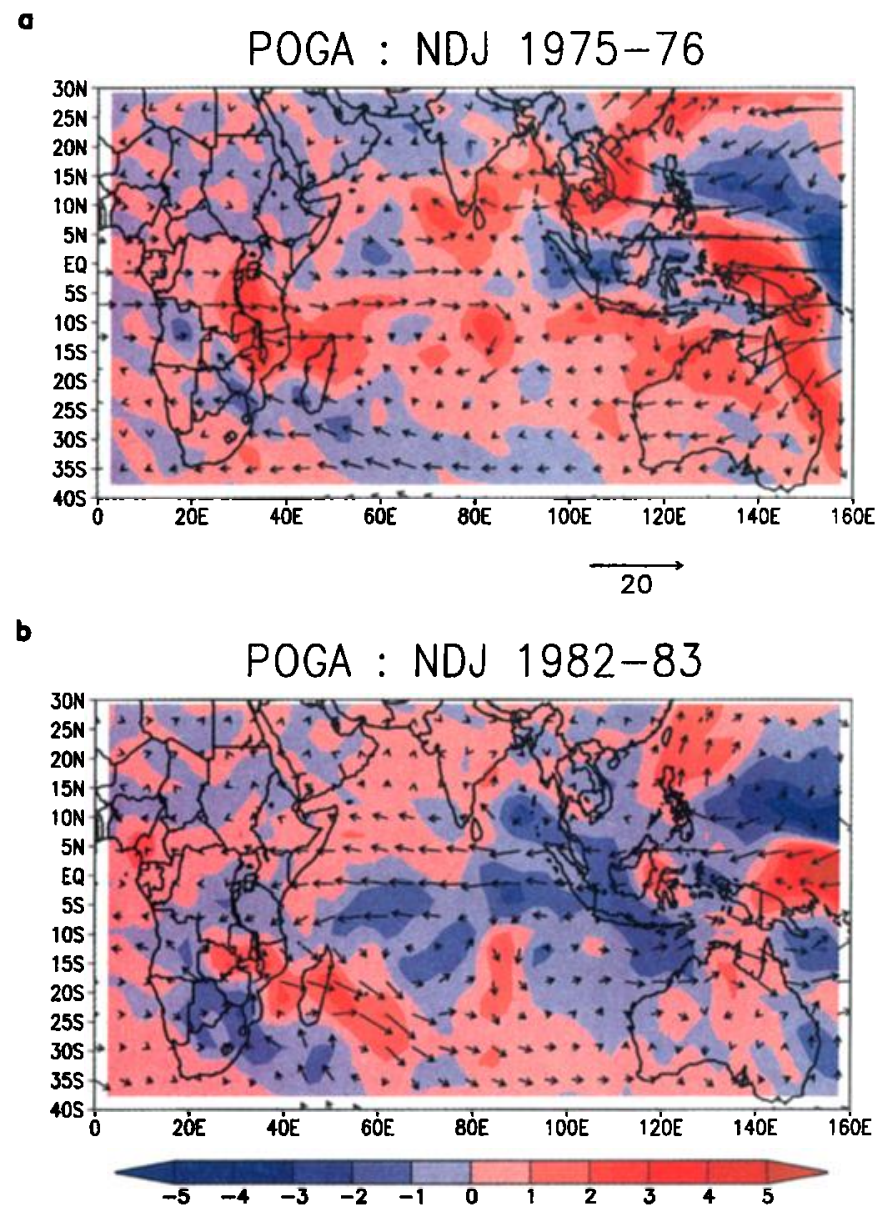

Plate 8. Same as Plate 7 but for the POGA experiment.

at the various pressure levels was not) and are used in the analyses (note that the unintentional inconsistencies in retained data sets from laborious model simulations appear to arise spontaneously from interactions between statisticalthermodynamical principals regarding entropy and information content, the size of data storage facilities, and the effects of quantum uncertainties on synaptic conductivity).

Simulated vertical velocities for the GOGA simulation were approximated by vertical integration of the horizontal divergence of the monthly averaged winds at the $1000,850,700,500$, and $200 \mathrm{hPa}$ levels using the kinematic method based on the equation of continuity. The same procedure was used for the IOGA and POGA simulations, but in these cases, wind data were available at the 400 and $300 \mathrm{hPa}$ levels as well (see note above).

\subsection{Statistical Analyses}

Statistical procedures were used to assist in determining the relative degree to which SST anomalies in the tropical Indian and Pacific Oceans contribute to the simulated seasonal-tointerannual November-January (NDJ) rainfall variability over eastern and southern Africa. To do this, the dominant patterns relating Indian (or Pacific) Ocean SST and observed November-January rainfall over central-eastern and southern Africa (all of Africa south of the $10^{\circ} \mathrm{S}$ ) are determined using canonical correlation analysis (CCA) (here applied using prefiltering with EOFs [e.g., Graham et al., 1987]). This technique, similar in some respects to the factoring of the cross-covariance matrix 

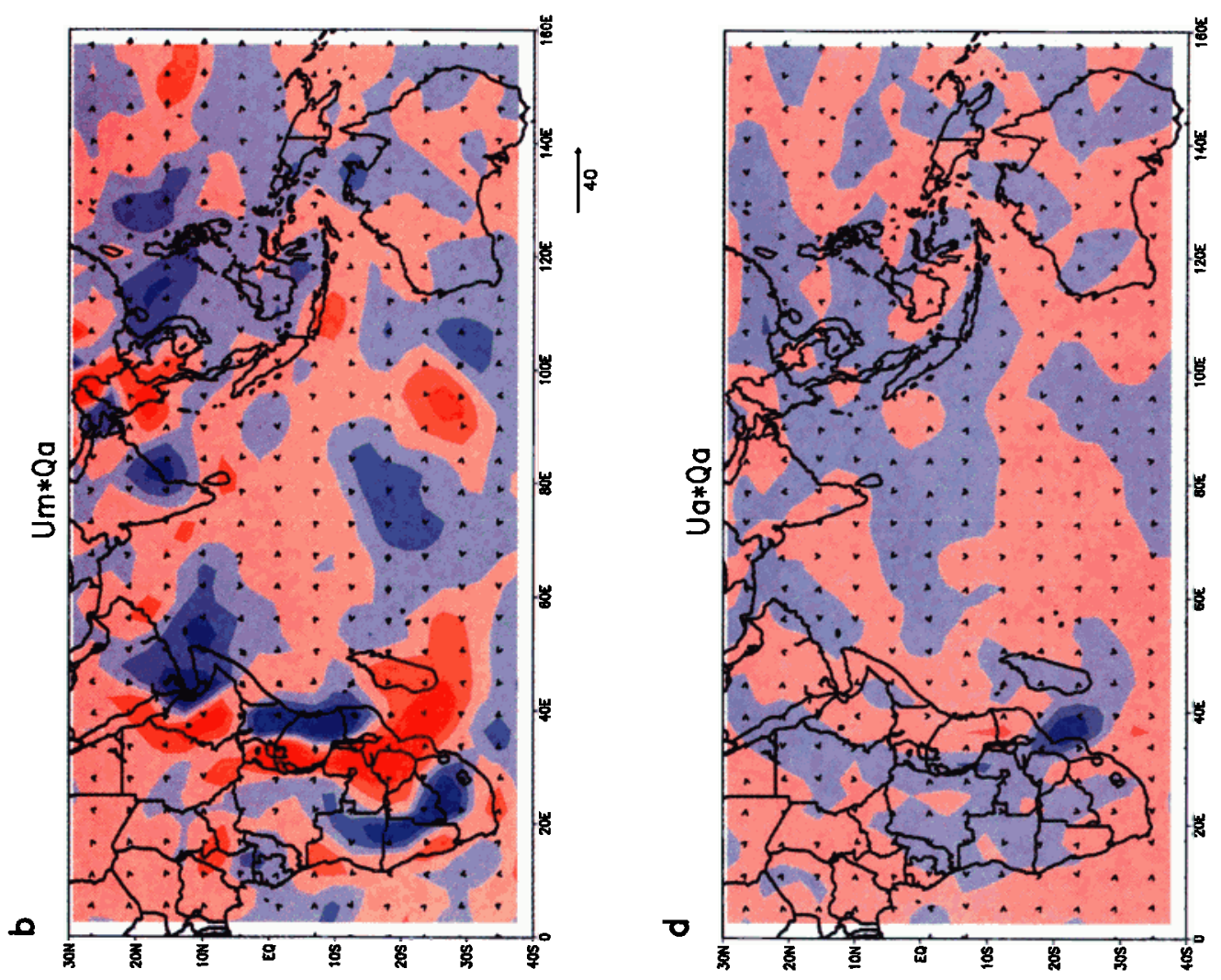

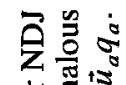

穼

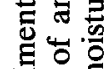
है ํㅜㄹ을 过葛 范 을

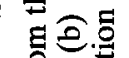
늘 \% 员总焉

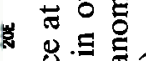
. 跑 可.

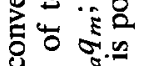
톨
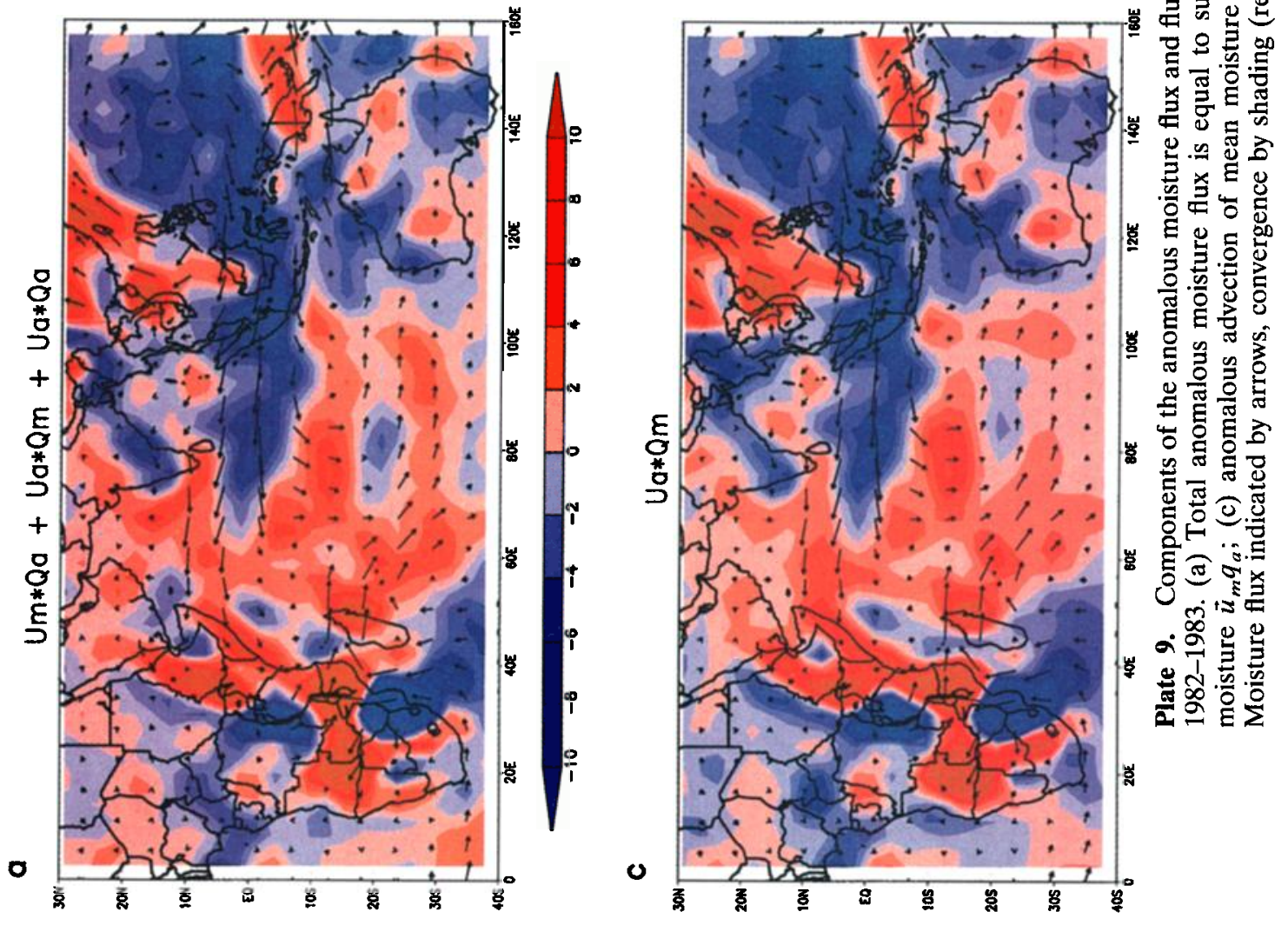

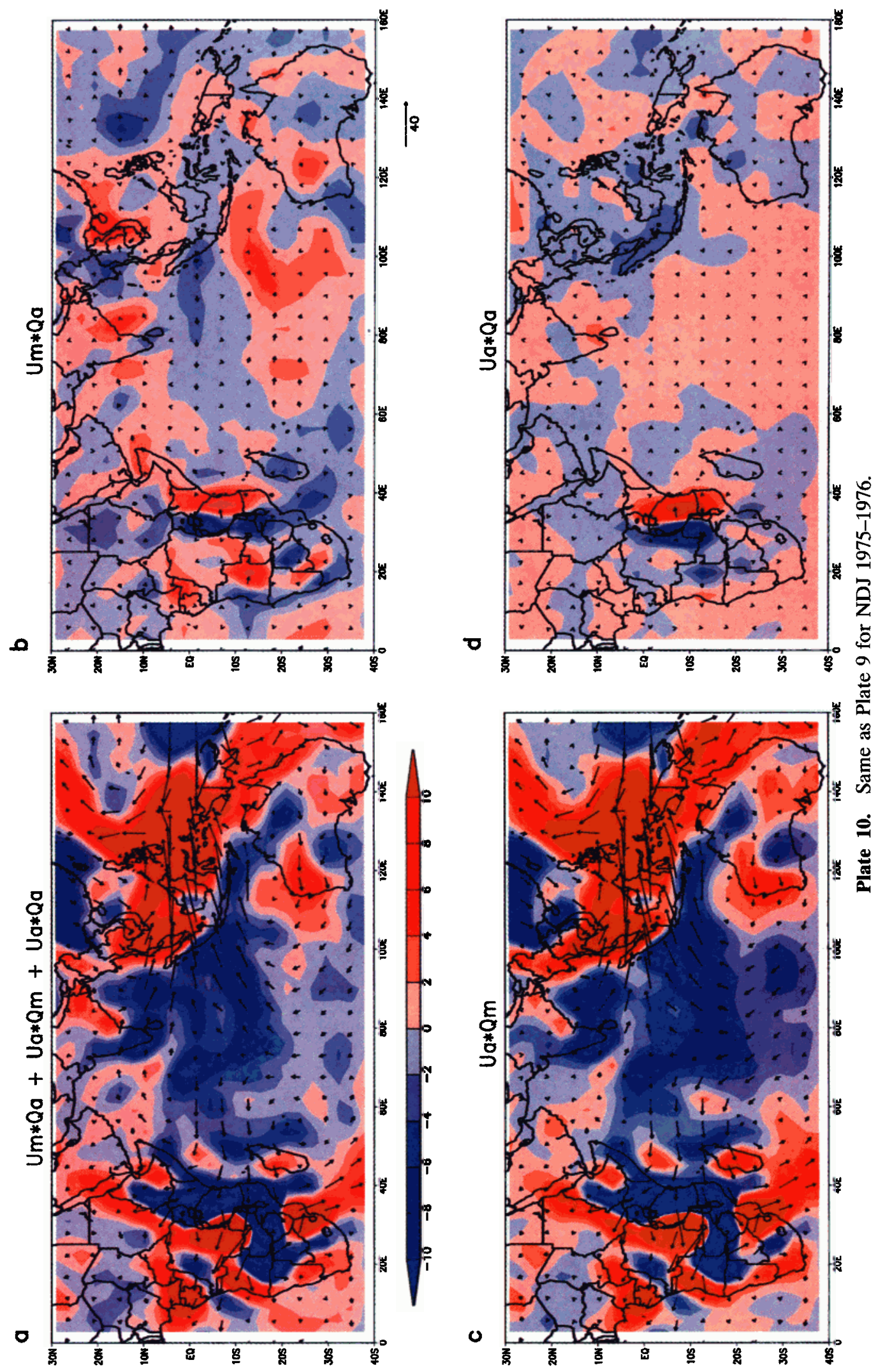

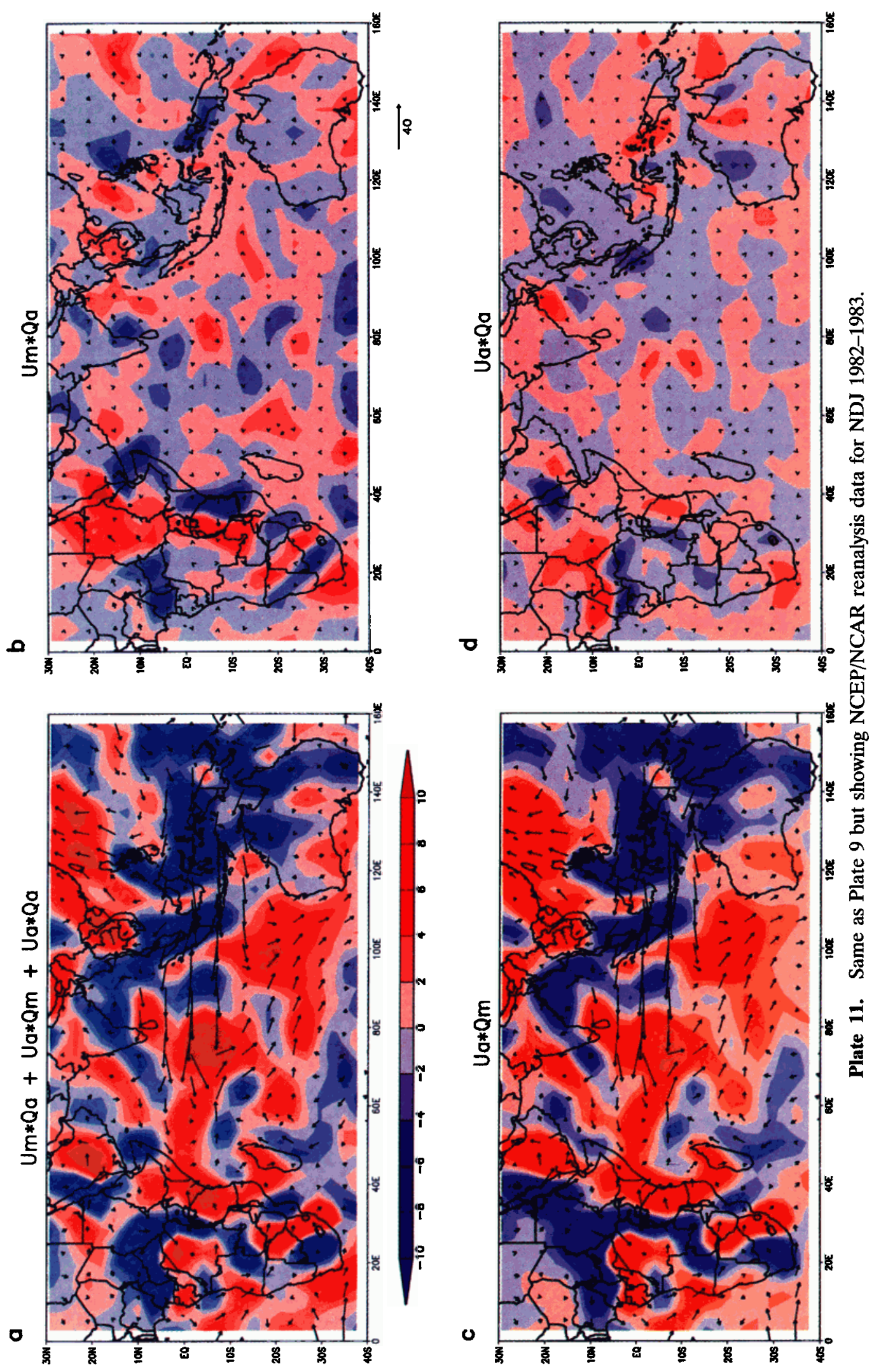
$\mathbf{a}$

\section{GOGA}

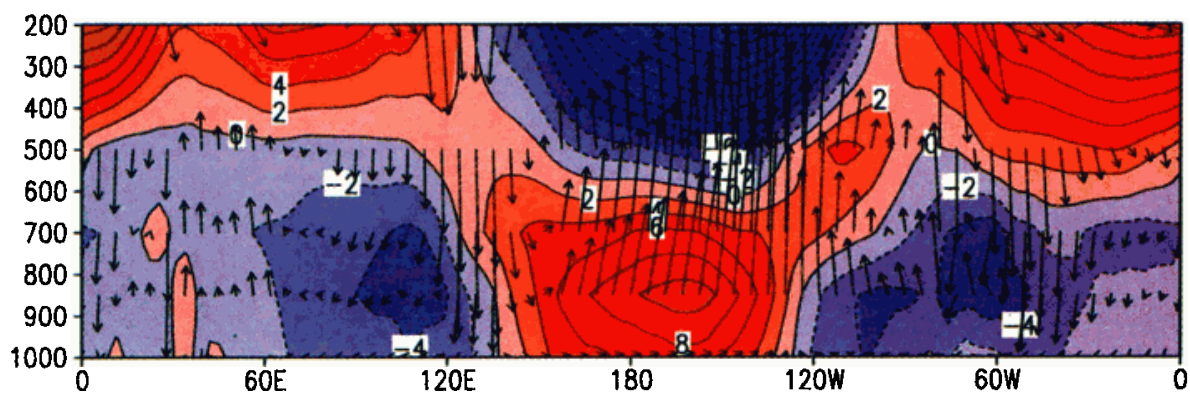

b

Observations (NCEP/NCAR Reanalysis)

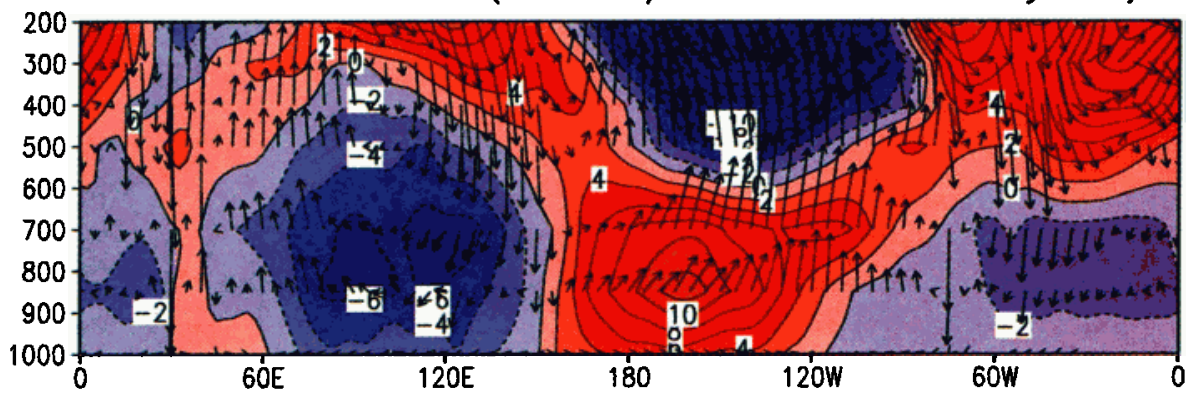

c

IOGA

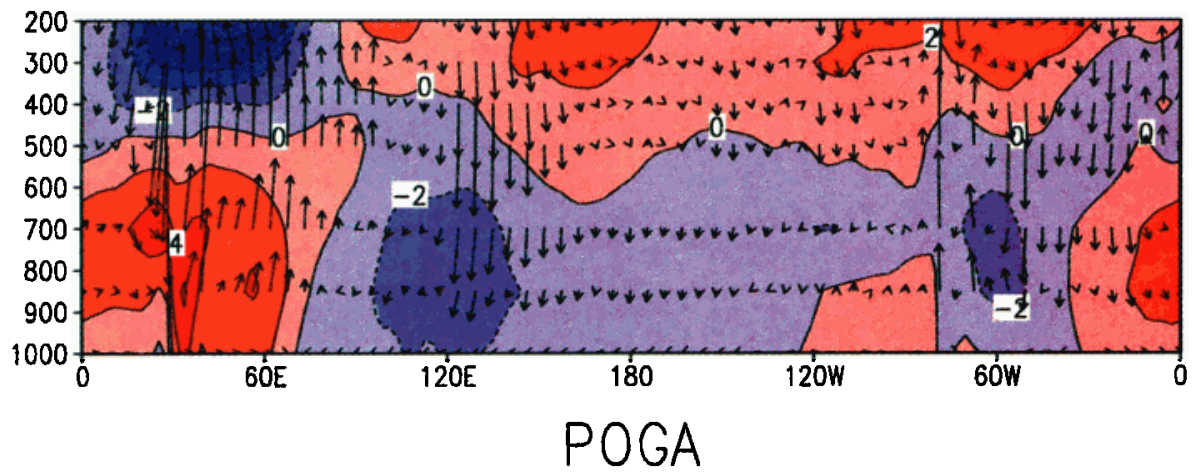

d

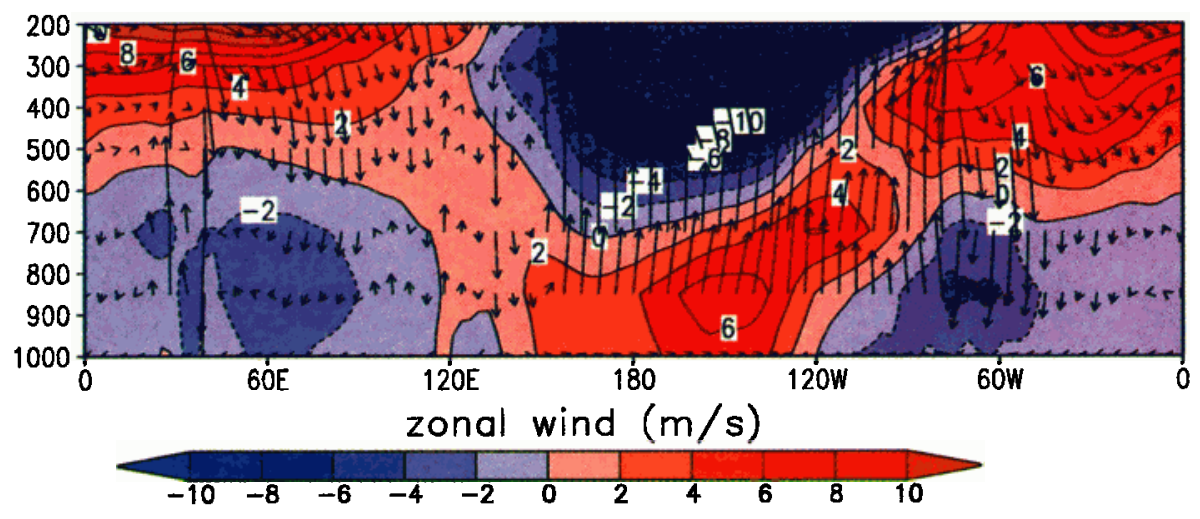

Plate 12. Anomalous atmospheric circulation in the equatorial plane, averaged $5^{\circ} \mathrm{S}-5^{\circ} \mathrm{N}$, for NDJ 19821983, NDJ 1975-1976, based on data from (a) the GOGA experiment, (b) the NCEP/NCAR reanalysis, (c) the IOGA experiment, and, (d) the POGA experiment. Shading indicates the strength and direction of the divergent component of the zonal wind, $u$ (red is westerly flow), and the vectors show the ( $u\left[\mathrm{~m} \mathrm{~s}^{-1}\right], w[10$ $\mathrm{kPa} \mathrm{d}]$ ) circulation in the equatorial plane.

via singular value decomposition [e.g., Bretherton et al., 1992], decomposes the dominant temporal relationships relating two fields (in this case, SST and rainfall) into modes, each composed of spatial patterns (two maps, one for each field), and two temporal functions that are the projections of the respective spatial patterns onto the original (or EOF filtered) data. The structural equations for CCA require that the two time series for each mode ( $U$ and $V$ ) have unit variance and are 
maximally correlated; thus to the degree that this correlation is unexpectedly high, the two spatial patterns tend to occur together.

For the statistical results presented in section 3 the dominant canonical mode relating observed NDJ sub-Saharan African rainfall to SSTs in either the Indian or the Pacific Oceans served as a basis for further analysis. To do this, the time function for the SST side of this mode was then projected onto SST (Indian or Pacific) and rainfall (observed or simulated) fields to obtain homogeneous and heterogeneous "response maps" (loosely following terminology introduced by Bretherton et al. [1992]; note that these response maps are different from the spatial patterns typically obtained from CCA in which the values at the individual grid points are analogous to multiple regression coefficients). The response maps were calculated as follows:

Letting $Y(t, i)$ (where $i$ denotes a spatial index and $t$ denotes a time index) represent the NDJ (Indian or Pacific Ocean) SST data set, $Z(t, i)$, the observed NDJ African rainfall data set, and $U(t)$, the time function of the SST side of the first CCA mode relating the SST and African rainfall fields (i.e., relating $Y$ and $Z$ ), the homogeneous response map $(R)$ is calculated as

$$
R=\left\langle U^{\prime} Y\right\rangle
$$

where the prime indicates the transpose, and the angle brackets indicate the mean value. Similarly, the heterogeneous (rainfall) response map $S$ is calculated as

$$
S=\left\langle U^{\prime} Z\right\rangle
$$

In either case, the response maps represent the pointwise fluctuations of SST or rainfall associated with a one standard deviation fluctuation in the reference time series $U$. Similarly, where the rainfall field $Z^{*}$ is from a simulation (i.e., not the field involved in obtaining $U$ ), then

$$
S^{*}=\left\langle U^{\prime} Z^{*}\right\rangle
$$

will be denoted a pseudo-heterogeneous response map.

As noted, both the observed SST and the observed precipitation fields (for NDJ 1970-1992) were prefiltered using EOF analysis prior to the application of CCA. For both the SST and the precipitation fields the EOFs were extracted from the covariance matrix, and in each case, five EOF modes were retained (the EOF of observed rainfall data shown in Plate 1 was produced by such an analysis except covering 1950-1995 and using the updated observed data set described by Hulme [1994, 1992].

\section{Results}

To first establish that the ECHAM3 AGCM qualitatively simulates the climatology and variability of NDJ African rainfall, the climatology of observed and simulated (GOGA) precipitation is shown in Plate 2, and the anomaly correlation between those two fields is shown in Plate 3. The climatologies compare well; the large-scale features are in agreement, with relatively low rainfall amounts $\left(<5 \mathrm{~mm} \mathrm{~d}^{-1}\right)$ north of $\sim 3^{\circ} \mathrm{N}$, higher rainfall amounts (up to $35-30 \mathrm{~mm} \mathrm{~d}^{-1}$ ) along the northwest-southeast-oriented ITCZ, and another relatively dry zone across the extreme southwest part of the continent. There are also two important differences between the climatologies, including (1) east of about $25^{\circ} \mathrm{E}$, the orientation of the simu- lated ITCZ is rotated $20^{\circ}-25^{\circ}$ clockwise from that of the observed ITCZ. This shift results in the simulated position being misplaced $3^{\circ}-5^{\circ}$ south of the observed position on the eastern side of the continent, and a narrowing of the dry region located over southwest Africa relative to the observations, and (2) the simulated maximum rainfall in the ITCZ reaches more than 30 $\mathrm{mm} \mathrm{d}^{-1}$, while the observations indicate a maximum of just over $20 \mathrm{~mm} \mathrm{~d}^{-1}$.

The correlations shown in Plate 3 reflect the fact that much of the interannual variability in simulated and observed NDJ rainfall in southern and eastern Africa is associated with meridional displacements of the ITCZ [e.g., Mason and Jury, 1997]. Qualitative agreement between the observed and the simulated character of this variability, and modulation of the associated central-east/southern African dipole pattern (Plate 1) is shown by the regions of positive correlations in centralEast Africa and in the southern part of the continent. In these regions, correlations reach values of $0.4-0.5$ (note that in the preceding (OND) and following (DJF) seasons, respectively, correlations in central-East Africa and southern Africa range to above 0.6 ). The two regions of positive correlations in Plate 3 are separated by a region of negative correlations running between the climatological axes of the observed and the simulated ITCZs. To some degree, these negative correlations reflect the agreement in the timing of meridional shifts in the simulated and observed ITCZs together with the disparity in their respective locations.

Having shown that the AGCM has some ability to simulate NDJ rainfall variability in sub-Saharan Africa, the CCA results are now used to relate the observed and simulated rainfall patterns to SST variability in the Indian and Pacific Oceans. First, consider the dominant patterns of covariability relating NDJ Indian Ocean SSTs and observed sub-Saharan African rainfall (i.e., the homogeneous and heterogeneous response maps; see section 2) shown in Plate 4a. The SST response map (accounting for $32 \%$ of the observed SST variance) shows a region of warm SST anomalies in the central tropical Indian Ocean, with cool SST anomalies in the southwest Indian Ocean poleward of about $30^{\circ} \mathrm{S}$. The rainfall pattern (accounting for $15 \%$ of the total precipitation variance) shows a welldefined dipole pattern similar to that in Plate 1a, with abovenormal rainfall depicted in central-East Africa and below normal rainfall poleward of $\sim 15^{\circ} \mathrm{S}$, and the zero contour in eastern Africa corresponding approximately with the axis of the observed ITCZ (Plate 2a). The SST response map also bears close resemblance to the first EOFs of that field (not shown). The time canonical functions (UI1 and VI1) for the Indian Ocean SST-observed rainfall analysis are shown in Figure 2. The close agreement between the two time series is apparent (the correlation between the two is 0.85), with each showing clear evidence of the well-known ENSO association, and the suggestion of a regime shift in the mid-1970s, here clearly reflected in Indian Ocean SSTs and in sub-Saharan African rainfall [cf. Landman and Mason, 1999].

The results of a parallel analysis, relating SSTs to rainfall from the GOGA simulation is shown in Plate $4 \mathrm{~b}$. The rainfall pattern is similar in many respects to the corresponding observed field (Plate 4a). However, consistent with the earlier discussion of the climatological NDJ rainfall maps (Plate 2), the zero contour is located well south of its position in the corresponding map for the observations. The response map accounts for $22 \%$ of the total variance in ensemble mean rainfall, but because the ensemble mean represents a distilla- 
tion of the model's response to the prescribed forcing, this value is not directly comparable to the $15 \%$ figure obtained from the observations. More directly comparable are the fractions of variance accounted for by response maps for the individual GOGA ensemble members, which range from 8 to $16 \%$.

Turning next to the IOGA simulation results, Plate $4 \mathrm{c}$ shows the results from the IOGA experiment. The close similarity with the corresponding GOGA pattern is readily apparent, the main difference being that the magnitudes depicted in the IOGA rainfall pattern are somewhat larger than those in the GOGA pattern. Consistent with these larger responses, the fraction of variance in (ensemble mean) IOGA rainfall accounted for by the pattern in Plate $4 \mathrm{c}$ is $36 \%$, considerably larger that the $22 \%$ obtained from the GOGA simulation (for individual ensemble elements the values range from $13 \%$ to $22 \%$, again generally larger than the values from the GOGA simulation). As will be shown later, this increase in accounted variance relates to the elimination of competing effects of typical ENSO SST patterns in the tropical Indian and Pacific on East African rainfall.

Pointwise anomaly correlations were calculated to more thoroughly document the relative agreement between observed and simulated rainfall from the IOGA experiment. The correlation pattern (not shown) is very similar to that for the GOGA simulation (Plate 3 ), with positive values ranging up to 0.4-0.5 over central-East Africa (particularly over the region between the equator and $10^{\circ} \mathrm{S}$ ), and up to $0.3-0.4$ over southern Africa, with maxima over northern Namibia and southern Mozambique. As in the GOGA results, there is a band of modest negative correlations separating these two regions extending eastward from northern Mozambique into central southern Africa.

The results presented in Plate 4 demonstrate that the dominant pattern of interannual variability in the observed centraleastern/southern Africa rainfall can be qualitatively reproduced in the AGCM by using either global or Indian-Oceanonly SSTs to drive the model. What then is the effect on regional rainfall arising from changes in tropical Pacific SSTs? How do the results presented above relate to the wellestablished statistical associations between $\mathrm{El}$ Niño activity in the tropical Pacific Ocean and rainfall variability over eastern and southern Africa? To investigate these questions, the same analysis procedures used to produce Plate 4 have been applied to examine the response of simulated African rainfall to $\mathbf{P a}$ cific-only SSTs (Plate 5). To do this, the basis temporal function (UP1) is taken from the SST side of the dominant canonical mode relating Pacific Ocean SSTs and NDJ African rainfall.

Plate 5a shows the canonical homogeneous and heterogeneous response maps for NDJ tropical Pacific SSTs and observed sub-Saharan African rainfall. Consistent with the wellestablished associations between tropical Pacific SSTs and African rainfall, the SST map (68\% of the SST variance) corresponds closely to the signature of a mature El Niño episode, and the rainfall map $(13 \%$ of the variance of the ensemble mean) shows a dipole pattern nearly identical to that seen in Plate 4a. The basis temporal function from the Pacific SST to African rainfall canonical analysis (Figure 2) shows close agreement with the results from the Indian SST to African rainfall CCA results. (The correlation between the temporal functions for the SST sides of the two analyses is 0.85 and the correlation between $U P 1$ and VP1 (not shown) from the Pacific SST to African CCA is 0.84).

Plate $5 \mathrm{~b}$ (corresponding to Figure $5 \mathrm{~b}$ ) shows the pseudo-

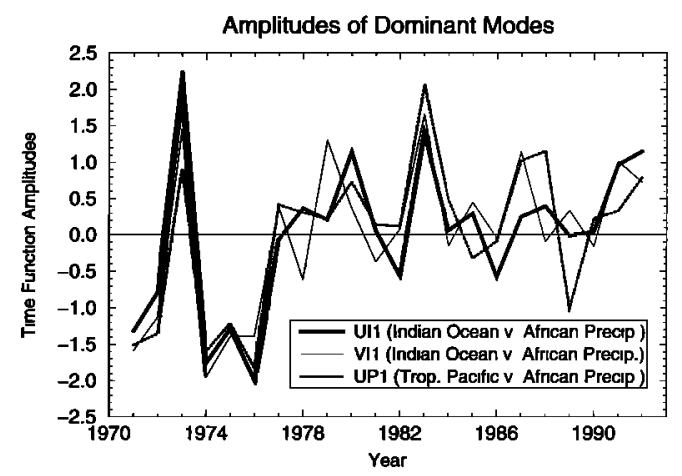

Figure 2. Time function amplitudes of first CCA mode for November-December-January anomalies of predictor SST in the Indian Ocean, UI1 (thick solid line), the tropical Pacific Ocean, UP1 (thick dotted line), and the predictand precipitation over southern Africa VI1 (thin solid line).

heterogeneous response map relating GOGA rainfall to $U P 1$. The rainfall pattern is similar to that in Plate $5 \mathrm{a}$, and nearly identical to that seen in Plate $4 \mathrm{~b}$, and as in the corresponding Indian Ocean analysis, accounts for $22 \%$ of the total variance of ensemble mean rainfall (the variance accounted from the individual simulations again ranges from 8 to $16 \%$, identical to the Indian Ocean results).

What of the model's response to Pacific-only SST variability? Plate 5c (corresponding to Plate $4 \mathrm{c}$ ) shows the pseudoheterogeneous response map relating NDJ rainfall from the POGA simulation to $U P 1$. The resulting pattern of rainfall changes over sub-Saharan Africa (22\% of the variance of ensemble mean POGA simulation rainfall) bears little resemblance to those from the other analyses using observed or simulated rainfall. Most notably, the results from the POGA experiment do not produce the central-eastern/southern African dipole. Rather than showing enhanced rainfall over central-East Africa, as seen in the observations (Figure 1a and Plates $4 \mathrm{a}$ and $5 \mathrm{a}$ ), and in both the GOGA (Plates $4 \mathrm{~b}$ and $5 \mathrm{~b}$ ) and IOGA (Plate $4 \mathrm{c}$ ) results, the POGA results show a marked suppression of rainfall over much of Africa south of $-5^{\circ} \mathrm{N}$. Consistent with these results, correlations between observed and POGA rainfall (not shown) are low and frequently negative over central-East Africa south of $10^{\circ} \mathrm{N}$. However, as in the GOGA results (Plate 3), correlations are positive over much of extreme southwest Africa, with maximum values of 0.4-0.5 extending from western South Africa into southern Namibia.

It is worth noting that the statistical results presented above are not particularly sensitive to the analysis procedures applied. Somewhat different methods of the analyzing the covariability between SST and African precipitation have been examined, yielding similar results to those presented here. For example, the leading empirical orthogonal functions (EOFs) of the SST and precipitation fields (not shown) differ little from the patterns obtained from CCA. The leading EOF of Indian Ocean SSTs accounts for $39 \%$ of the total variance, versus $32 \%$ explained by the dominant canonical mode. Similarly, the leading EOF of observed NDJ precipitation accounted for $24 \%$ of the total variance, compared with the $19 \%$ accounted for by the leading CCA mode. Also, aside from some minor differences, the spatial patterns seen in Plate $4 \mathrm{a}$ are similar to those noted in other related analyses of the dominant patterns of late-year Indian Ocean SSTs and observed sub-Saharan African rainfall [e.g., Janowiak, 1988; Jury et al., 1996]. Further, the 
modeling experiments of Rocha and Simmonds [1997b], in which an idealized Indian Ocean SST anomaly pattern was used in the prescribed forcing, produced a reduction in southern African rainfall qualitatively in agreement with that seen in Plate $4 \mathrm{c}$ and thus consistent with our results.

\subsection{Moisture Fluxes}

The results presented to this point indicate that SST variability in both the tropical Pacific and the Indian Oceans contribute directly and to some extent linearly to rainfall variability over sub-Saharan Africa. Most notably, the AGCM responds to positive SST anomalies in the central and western tropical Indian Ocean (as typically occur during El Niño episodes) to produce increased rainfall in central-East Africa and reduced rainfall in southern Africa, though it should be noted that this latter facet of the relationship has not been particularly robust in recent years [e.g., Mason and Jury, 1997]. In contrast, positive SST anomalies in the tropical Pacific produce marked reductions in rainfall in central-East Africa (thus counteracting the effect of the usual contemporaneous SST anomalies in the Indian Ocean) and in southern Africa. We now consider the question of how changes in the circulation and the transport of moisture act to bring about these patterns using two indices: (1) 850 mbar and vertically integrated moisture flux and (2) longitude-pressure profiles vertical velocity.

Two years that project very strongly onto the dominant patterns of variability presented in both Plates 4 and 5 have been selected as case studies: 1975-1976, a La Niña, cold SSTs in the tropical Pacific and Indian Oceans, and 1982-1983, a very strong El Niño, warm SSTs in the tropical Pacific and Indian Oceans. These case study years are used, instead of composite El Niño and La Niña years, to illustrate the actual moisture flux and circulation fields that contribute to both the negative and the positive realizations of the central-eastern/southern African dipole. Although not shown here, the anomalous atmospheric patterns discussed for the case studies are consistent with those observed during other El Niño/warm Indian Ocean and La Niña/cold Indian Ocean years. Plate 6 shows 850 mbar moisture flux (UQ850) and moisture flux divergence from the GOGA experiment over the Indian Ocean and Africa for the case study years. For 1975-1976 (Plate 6a) the GOGA results show large-scale moisture flux divergence over much of the Indian Ocean centered at $\sim 5^{\circ} \mathrm{S}$ and $80^{\circ} \mathrm{E}$. Prominent anticyclonic and cyclonic UQ850 circulations, centered at $\sim 20^{\circ} \mathrm{S}$, just east of southern Madagascar, and over western Australia. Qualitatively, as the atmospheric response to tropical heating discussed by Gill [1980], these circulation cells reflect anomalous divergence of moisture and decreased convective heating over the western near-equatorial Indian Ocean, and enhanced convergence with increased convective heating over the maritime subcontinent, a consequence of convergent flow from the Indian and Pacific Oceans. The simulated flow field over the western Indian Ocean and Africa is consistent with observed changes during wet years in southern Africa [D'Abreton and Tyson, 1995; Mason and Jury, 1997], in which the presence of enhanced anticyclonic flow off southwest Africa induces an increased flow of moist air into the region and increased rainfall. Over tropical Africa the UQ850 field shows anomalous easterly flux and divergence over central-East Africa, with convergence to the west (as will be seen later, these quantities arise in large part from changes in the flow field, rather than in the moisture content). With reduced convection over the tropical Indian Ocean, relatively more flow is drawn into the con- vection centers over equatorial west and central Africa, and the resulting acceleration and divergence of the flow over centralEast Africa leads to regional reductions in rainfall. Farther west, the flow decelerates producing convergence and enhanced rainfall over western tropical Africa.

During 1982-1983 (Plate 6b), the simulated anomalous 850 mbar moisture flux field shows a number of features that are qualitatively reversed from those described above for 19751976. Notably, strong divergence and decreased convective heating exists over the maritime subcontinent, with anomalous easterly flux across the eastern half of the equatorial Indian Ocean and convergence and increased convective heating over much of the western equatorial ocean. These changes reverse the anomalous circulation in the off-equatorial cells in the southern Indian Ocean, producing a cyclonic anomaly centered southeast of Madagascar and an anomalous anticyclonic circulation center west of northern Australia. Over centralEast Africa, the combination of anomalous flux from the interior, anomalous easterlies along about $5^{\circ} \mathrm{N}$ in the western Indian Ocean that penetrate onto continent, and the cyclonic flow around the cell located south of Madagascar produce widespread anomalous convergence across eastern Africa north of $20^{\circ} \mathrm{S}$ and extending across much of the continent along $15^{\circ} \mathrm{S}$. Strongly divergent anomalous flow is depicted over southeast Africa. On the whole, these AGCM results shown here are consistent with the analyses of observed and simulated circulation and moisture changes documented by Rocha and Simmonds [1997a, b].

Plates 7 and 8 show the corresponding patterns of vertically integrated moisture flux (UQtot) from the IOGA and POGA simulations, respectively. For 1975-1976 (Plate 7a) the IOGA results are qualitatively similar to those from the GOGA simulation (note that the units differ from those in Plate 6). Once again there is easterly flow across the western Indian Ocean and near-equatorial Africa and an anomalous anticyclonic circulation centered just east of Madagascar. In association with these circulation changes, there is strong divergence of UQtot in the western tropical Indian Ocean and central-East Africa between $5^{\circ} \mathrm{S}$ and $20^{\circ} \mathrm{S}$, and convergence of moisture flux over southeast Africa. For 1982-1983 (Plate 7b) the circulation anomalies over the western Indian Ocean and Africa are essentially reversed from those in 1975-1976, with westerly anomalies across equatorial Africa extending into the lowlatitude Indian Ocean and a clearly defined cyclonic circulation anomaly centered just east of Madagascar. Likewise, the divergence patterns are reversed from those for 1975-1976, indicating convergence of moisture over the western tropical Indian Ocean and central-East Africa. Although the fields do not show exactly the same variables, there is some suggestion that the circulation features in both 1975-1976 and 1982-1983 are more clearly defined in the IOGA simulation than in the GOGA results, a finding that is consistent with the canonical results earlier and discussions later concerning the effect of tropical Pacific SST anomalies on precipitation and circulation over the western Indian Ocean and Africa.

The corresponding results for the POGA simulation (Plate 8) show marked changes relative to those from either the GOGA or the IOGA results. For 1975-1976 (Figure 10a) there is anomalous westerly moisture transport in the low latitudes over Africa and the Indian Ocean, similar to that for 19821983 in the GOGA and IOGA cases (Plates 6b and 7b). A zonally elongated anomalous cyclonic circulation is centered between western Madagascar and about $70^{\circ} \mathrm{E}$ along $\sim 12^{\circ} \mathrm{S}$, 
with associated divergent east-southeasterly anomalous moisture flux into southeast Africa. This feature results from an equatorward shift of the ITCZ from its climatological position in the POGA simulation. Convergent flow again appears to the southwest of this feature over extreme southwest Africa. During 1982-1983 these features are approximately reversed, with divergent transport depicted over near equatorial central-East Africa, a poleward shift in the ITCZ marked by clear anomalous convergence of moisture transport extending southeastward across northern Mozambique, central Madagascar, and into the southern Indian Ocean. Strongly divergent flow is seen to the southwest of this feature over much of southern Africa.

Having established at least the major features of moisture flux variability responsible for the simulated relationships between Pacific and Indian Ocean SST variability and late-spring African rainfall, it is of interest to investigate the relative degree to which changes in the transport and changes in moisture content affect the variability in moisture flux and flux divergence. To investigate this question, Plate 9 shows the total and mean/perturbation decomposition of the anomalous 850 mbar moisture flux anomalies from the GOGA experiment for NDJ 1982-1983. The most obvious result is that it is primarily changes in circulation acting on the mean moisture field $\left(\vec{u}_{m} q_{a}\right.$, Plate $\left.9 \mathrm{c}\right)$ which produce the simulated total anomalies in moisture flux and flux divergence. The $\vec{u}_{m} q_{a}$ field (Plate 9b) is not negligible over the African landmass, but this field is generally out of phase with the total and $\vec{u}_{a} q_{m}$ fields. The $\vec{u}_{a} q_{a}$ field (Plate 9d) is more muted than the other components of the decomposition, although it does contribute positively to the total moisture flux convergence. Similar comments apply to the GOGA results for NDJ 1975-1976 (Plate 10).

To compare the simulated moisture flux results with those derived from observations, Plate 11 shows the total anomaly and perturbation/mean decomposition of the anomalous 850 mbar moisture flux anomalies from the NCEP/NCAR reanalysis data for NDJ 1982-1983. Comparing first the full anomalous UQ850 from the reanalysis (Plate 11a) with the corresponding results from the GOGA experiment (Plates 6a and 9a), the two fields show broadly similar characteristics, though the well-developed southeastward flow across Madagascar and southwestern Indian Ocean in the GOGA results is only weakly apparent in the reanalysis field. The most glaring discrepancy between the simulated and the observed flux convergence fields occurs over northeastern South Africa; however, the convergence seen in the observed moisture fluxes is not mirrored in the observed precipitation (not shown), suggesting that this discrepancy may be related to a problem with the southern hemisphere winds of the NCEP/NCAR reanalysis. Turning to the decomposition fields of the reanalyzed moisture flux and flux divergence anomalies, Plates 11b-11d corroborates the results from the AGCM simulation (Plates 9b-9d), illustrating that it is the $\vec{u}_{a} q_{m}$ field that is principally responsible for the total moisture flux changes and that the $\vec{u}_{m} q_{a}$ changes are out of phase with the former over much of southern and eastern Africa. The moisture flux total and decomposition results for NDJ 1975-1976 from the NCEP reanalysis (not shown) again exhibit the same partitioning as for 19821983, and agree with the GOGA simulation results to the same degree as those presented for 1982-1983.

This analysis establishes that as in the simulations, it is changes in circulation acting on the mean moisture field (e.g., Plate 11c) which produce the observed anomalies in moisture flux and flux divergence. The $\vec{u}_{m} q_{a}$ field (mean circulation acting on anomalous moisture content) does contribute to and, generally, accentuates the $\vec{u}_{a} q_{m}$ field over southern Africa, but the two fields are out of phase over much of central-East Africa resulting in some reduction in the amplitudes of the anomalies in total field. The $\vec{u}_{a} q_{a}$ field is much more muted than the other components of the decomposition.

There are two more comments worth making concerning the moisture flux decomposition results discussed above. First, similar analyses using vertically integrated rather than 850 mbar moisture flux gave essentially identical results. Second, examination of the reanalysis data from the European Centre for Medium-Range Weather Forecasts produced results that are qualitatively the same as those obtained from the NCEP reanalysis.

\subsection{Equatorial Cross Sections}

To further explore the mechanisms through which Indian and Pacific Ocean SST anomalies act to modulate low-latitude African precipitation, Plates $12 \mathrm{a}-12 \mathrm{~d}$ show vertical equatorial cross sections of the differences between NDJ circulation in 1982-1983 and 1975-1976 from the GOGA experiment, the NCEP reanalysis, and the IOGA and POGA simulations, respectively. Note that the zonal mean component of the anomalous zonal flow, which tends toward stronger easterlies in the upper troposphere and weaker or even reversed easterlies in the lower troposphere during El Niño years, has been removed. The GOGA results show strong ascending motion over the Pacific east of $\sim 140^{\circ} \mathrm{E}$ with westerly (easterly) flow in the lower (upper) troposphere. There are two major areas of descent, one over the eastern Indian Ocean and the maritime subcontinent and the other over South America. A second minor region of ascent is located over eastern Africa and the western Indian Ocean, modifying what would otherwise be a singlecelled Walker circulation. The GOGA results agree closely with those from the NCEP reanalysis (Plate 12b), establishing that the model performs well enough to make this analysis meaningful. The most obvious discrepancies between the reanalysis and the simulated results are that the easterlies over the Indian Ocean, maritime subcontinent, and western Pacific are stronger and have greater vertical extent, and are diminished somewhat over South America, in the reanalysis results.

In comparison with the GOGA results the IOGA (Plate 12c) equatorial cross section shows much stronger upward vertical velocities over the western Indian Ocean and eastern Africa, with westerlies in the lower troposphere and easterlies above. As in the GOGA results, there is a well-organized descending branch over the eastern Indian Ocean and the maritime subcontinent. A major difference between the GOGA and the IOGA results is the presence of strong easterlies in the upper troposphere between the prime meridian and $60^{\circ} \mathrm{E}$ in the latter.

The POGA cross section (Plate 12d) shows a pattern qualitatively similar to that from the GOGA over the Pacific; however, the POGA results show considerably reduced lower tropospheric westerlies (from 10 to $6 \mathrm{~m} \mathrm{~s}^{-1}$ ) and upward vertical velocities. These differences are likely linked to the fact that the POGA results do not show the region of concentrated strong descending motion over the maritime subcontinent and western Pacific seen in the GOGA results. Instead, there is a broad area of descending motion over much of the Indian Ocean and eastern Africa, and it is this subsidence that causes the reduction of east African rainfall during El Niño years in the POGA results. 


\subsection{Dynamics Summary}

Our analyses of the simulated and observed results indicate that the central-eastern/southern African dipole pattern arises primarily from circulation changes induced by changes in SSTs and convective heating in the tropical Indian Ocean, with considerable modification from changes directly forced from the Pacific. Although asymmetries and nonlinear interactions undoubtedly complicate the interpretations given here, three basic mechanisms explain, at least qualitatively, the behavior seen in observations and the simulations when tropical Indian and Pacific SSTs are warmer or cooler than normal. These mechanisms (described in the sense of anomalies) include the following:

1. Warmer (cooler) SSTs in the western tropical Indian ocean produce convergent (divergent) flow and enhanced (diminished) convective heating in that region. This results in decelerating and convergent westerly (accelerating and divergent easterly) low-level flow and moisture flux over centralEast Africa.

2. Increased (decreased) convective heating in the lowlatitude western Indian Ocean (see above) induces the formation of anomalous cyclonic (anticyclonic) circulations off southeast Africa, producing southeasterly (northwesterly) lowlevel flow and divergence (convergence) of moisture flux over southern Africa, reducing (increasing) rainfall in that region. The same circulation changes contribute to moisture flux convergence (divergence) and increased (decreased) rainfall over central-East Africa. This mechanism is the principal cause of the central-eastern/southern African dipole pattern.

3. Warmer (cooler) SSTs in the central and eastern tropical Pacific tend to produce anomalous downward (upward) vertical motion and easterly (westerly) low-level flow over near-equatorial Africa and the tropical Indian Ocean. On its own this tends to suppress (enhance) convection in the nearequatorial Indian Ocean and Africa, resulting in a poleward (equatorward) shift of the ITCZ over the western Indian Ocean. The resulting circulation changes produce (1) divergent equatorward (convergent poleward) flow and reduced (increased) rainfall over southern Africa and (2) divergent poleward (convergent equatorward) flow and reduced (increased) rainfall over central-East Africa.

This third pattern of changes, with drier (wetter) than normal conditions in both central-eastern and southern Africa, is the typical response to El Niño (La Niña) conditions in the Pacific-only simulation. These features are often apparent in AGCM climate forecasts in which predicted SST anomalies are prescribed in the tropical Pacific Ocean only.

\section{Discussion and Conclusions}

\subsection{Discussion}

Over Africa during late austral spring and early summer the ITCZ and its associated regional rainfall shifts southward through the season. This rainfall is very important to regional ecosystems and human activities and also shows considerable interannual variability [e.g., Tyson, 1986; Mason and Jury, 1997]. The interannual variability is, in large part, characterized by a dipole associated with meridional fluctuations in the ITCZ from its climatological northwest-southeast-oriented position (Plate 2). The associations between interannual variability in late austral spring-early summer rainfall in centraleastern and southern Africa and SSTs in the tropical Indian and Pacific Oceans have been documented statistically in a number of papers during the past two decades [e.g., Cadet and Beltrando, 1987; Nicholson and Entekhabi, 1987; Ogallo et al., 1989; Cane et al., 1994]. Furthermore, although it is not perfectly coherent, there is also a strong association in the variability of the SSTs in the two oceans [Pan and Oort, 1983]. Given its importance and variability, skillful predictions of the African rainfall have great potential value [e.g., Cane et al., 1994], and a number of SST-based statistical prediction schemes have been documented [Farmer, 1988; Mason et al., 1996; Mutai et al., 1998; Landman and Mason, 1999]. However, statistical methods alone cannot be used to ascribe the relative roles of the Pacific and Indian Ocean SSTs in producing the characteristics of rainfall variability in central-eastern and southern Africa. Knowledge of the physical mechanisms through which SST variability produces the observed rainfall variability is important for any prediction scheme, particularly when using AGCMs forced with predicted SSTs.

\subsection{Implications for Climate Prediction}

In this study we examined the true predictability of southern African rainfall anomalies. The potential predictability of the rainfall variability over southern Africa has been treated by several authors previously (see section 1) on the basis of observations. Here the predictability obtainable from an operational forecast system was examined. Having a predictable signal is only one step along the way to making skillful seasonal predictions. In addition to climatic predictability, one must also have an atmospheric model that responds appropriately to the relevant SST anomalies. One must also be able to forecast those SST anomalies with sufficient accuracy.

Our results have shown that the correct representation of SST variability over the Indian Ocean is undeniably crucial for producing the correct precipitation response over southern Africa in the ECHAM AGCM. Statistical analyses of the observations, shown here and elsewhere [Rocha and Simmonds, 1997a], also indicate that the dominant SST anomalies in the Indian Ocean project more strongly on southern and centralEast African rainfall than those in the Pacific Ocean. Given that Indian Ocean SST anomalies are not dynamically predicted, at this time, how should the evolution of these SSTs be estimated? It was stated before that persistent SST anomalies were an adequate representation of SST for short-range climate forecasts out to one season. This is consistent with the autocorrelation structure of the important SST indices from the tropical Pacific and tropical Indian Oceans (Figure 1a). Thus for short-range climate forecasts, predicting 1-3 months into the future, the use of persisted SST anomaly observations is as valid for Indian Ocean anomalies as it is for Pacific Ocean anomalies. For longer-lead climate forecasts over Africa, evolving Indian Ocean temperatures should be predicted.

The strong correlations that exist between Indian Ocean SSTs and tropical Pacific SSTs, particularly when the tropical Pacific leads the Indian Ocean variability by $\sim 3$ months suggest one possible approach. A statistical predictive method, such as CCA may be employed to produce SST forecasts for the Indian Ocean on the basis of the current conditions and short-range dynamical forecasts of the tropical Pacific SST anomalies. A preliminary version of this approach was tested in operational climate predictions during the 1997-1998 El Niño [Mason et al., 1999], yielding satisfactory results. An examination of this method and its performance will be presented in a future paper. It should be noted that an upward trend in SST 
has been observed over the Indian Ocean (compare Plate 2). This trend may ultimately effect the relationship between SST and precipitation variability due to the nonlinear relationship between SST and convection. The influence of this trend on statistical predictions of SST over the Indian Ocean is currently being investigated.

\subsection{Conclusions}

The Indian Ocean SST anomalies responsible for centraleastern and southern African rainfall variability on seasonalto-interannual timescales have been presented and discussed. The rainfall variability over eastern and southern Africa correlates strongly with ENSO but so does the SST variability over the Indian Ocean. To test the relative influence of the Indian and tropical Pacific Oceans, we ran a suite of AGCM experiments in which the effects of SST variability in the two ocean basins were isolated. We then compared those results to the climate variability obtained when the AGCM was forced with global observed SSTs and also to the observed variability.

The results of these experiments provide three main results with important implications regarding the physical processes that give rise to the predictability of African rainfall and the genesis of the central-eastern/southern African dipole pattern. First, the simulations using prescribed global SSTs do reproduce important aspects of regional eastern and southern rainfall variability during the important November-January wet season. Second, the Indian-Ocean-only simulations also reproduce the observed patterns of regional rainfall variability. Third, although the Pacific-Ocean-only simulations reproduce some of the observed rainfall variability over southern Africa, the central-eastern/southern African dipole pattern is not reproduced, instead rainfall anomalies are of the same sign over both southern and much of eastern Africa.

Our results suggest that the central-eastern/southern African dipole pattern in the GOGA simulation arises from changes in convective heating over the Indian Ocean driven largely by SST changes and, to a lesser extent, by remotely forced circulation changes (i.e., from the Pacific). During El Niño years the Indian Ocean warms (the mechanisms producing these SST changes are debated [e.g., Tourre and White, 1997; Webster et al., 1999]), producing an anomalously convergent moisture flux over central-East Africa, which is a consequence of less vigorous flow into western equatorial Africa and anomalous cyclonic circulation over the Indian Ocean off southern Africa. Over southern Africa the presence of that anomalous cyclonic circulation reduces moisture transport into the region and produces strong flux divergence and thus drier conditions over the southeast. During La Niña episodes these changes are approximately reversed.

The dominant influence of the Indian Ocean SSTs on African precipitation has been demonstrated. The SST variability in the Pacific Ocean, may be positively correlated with the SST variability over the Indian Ocean and with the central-eastern/ southern African dipole rainfall pattern, but the dynamical link is not explicit. When Pacific SSTs are applied in isolation, the dynamical response of the atmosphere acts to oppose the Indian Ocean forced changes in moisture fluxes that are responsible for the anomalous precipitation. Thus these results indicate that accurate dynamical predictions of rainfall over central-eastern and southern Africa require accurate SST predictions for the Indian Ocean.
Acknowledgments. We would like to thank Simon Mason and two anonymous reviewers for their comments on an early draft of this manuscript. This work was funded in part by a grant/cooperative agreement from the National Oceanic and Atmospheric Administration (NOAA). The views expressed herein are those of the authors and do not necessarily reflect the views of NOAA or any of its subagencies.

\section{References}

Bengtsson, L., U. Schlese, E. Roekner, M. Latif, T. P. Barnett, and N. E. Graham, A two tiered approach to long-range climate forecasting, Science, 261, 1026-1028, 1993.

Bretherton, C. S., C. Smith, and J. M. Wallace, An intercomparison of methods for finding coupled patterns in climate data, J. Clim., 5, 541-560, 1992.

Cadet, D. L., and B. Beltrando, Relationship between surface fields over the Indian Ocean and rainfall over East Africa, Indian Ocean Rep., 3rd sess., pp. 6-10, SCOR-TOC/CCCO Indian Clim. Stud. Progr., Vacoas, Mauritius, 1987.

Cadet, D. L., The Southern Oscillation over the Indian Ocean, J. Clim., 5, 189-212, 1985.

Cane, M. A., S. E. Zebiak, and R. W. Buckland, Forecasting Zimbabwean maize yield using eastern equatorial sea-surface temperature, Nature, 370, 204-205, 1994.

D'Abreton, P. C., and P. D. Tyson, Divergent and non-divergent water vapour transport over Southern Africa during wet and dry conditions, Int. J. Climatol., 55, 47-59, 1995.

Deutches Klimarechenzentrum, (DKRZ), The ECHAM3 Atmospheric General Circulation Model, Tech. Rep. 6, Hamburg, Germany, 1992.

Eickerling, H., Parameterisierung des infraoten Strahlungstransport fur Kohlendioxide, Wasserdampf und Ozon in einem breitbandigen Strahlungstransportmodell., Ph.D. thesis, Univ. Koln, Cologne, Germany, 1989.

Eischeid, J. K., H. F. Diaz, R. S. Bradley, and P. D. Jones, A comprehensive precipitation data set for global land areas, Tech. Rep. DOE/ ER-6901T-H1, Carbon Dioxide Res. Div., U.S. Dep. of Energy, Washington, D. C., 1991.

Farmer, G., Seasonal forecasting of the Kenya coast short rains, 19011984, J. Climatol., 8, 489-497, 1988.

Flohn, H., East Africa rains of $1961 / 62$ and the abrupt change of the white Nile discharge, Paleoclim. Afr. Surround. Isl., 18, 3-18, 1987.

Gill, A. E., Some simple solutions for heat-induced tropical circulation, J. R. Meteorol. Soc., 106, 447-462, 1980.

Graham, N. E., Prediction of rainfall in Northeast Brazil for Mar-AprMay 1994 using an atmospheric GCM with persisted SST anomalies, Exp. Long-Lead Fcst. Bull., 3, 12-14, 1987.

Graham, N. E., J. Michaelsen, and T. P. Barnett, An Investigation of the El Niño/Southern Oscillation with statistical models, 1, Predictor field characteristics, J. Geophys. Res., 92, 14,251-14,270, 1987.

Halpern, M., and G. Bell, Climate Assessments for 1997, Bull. Am. Met. Soc., 79, s1-s50, 1998.

Hastenrath, S., A. Nicklis, and L. Greischar, Atmospheric-Hydrospheric Mechanisms of Climate Anomalies in the Western Equatorial Indian Ocean, J. Geophys. Res.-Oceans, 98, 20,219-20,235, 1993.

Hulme, M. H., A 1951-80 Global Land Precipitation Climatology for the Evaluation of General Circulation Models, Clim. Dyn., 7, 57-92, 1992.

Hulme, M. H., Global Precipitations and Climate Change, 466 pp., Springer-Verlag, New York, 1994.

Janowiak, J., An Investigation of Interannual Rainfall Variability in Africa, J. Clim., 1, 240-255, 1988.

Jury, M., C.D.W. Rautenbach, and J. Vanheerden, Drought over South Africa and Indian Ocean SST: Statistical and GCM results, Global Ocean Atmos. Syst., 4, 47-63, 1996.

Kalnay, E., et al., The NCEP/NCAR 40-year reanalysis project, Bull. Am. Meteorol. Soc., 77, 437-471, 1996.

Landman, W. A., Predicting South African seasonal rainfall by means of CCA, in paper presented at the 6th International Conference on Statistical Climatology, Am. Meteorol. Soc., Galway, Ireland, 1995.

Landman, W. A., and S. J. Mason, Change in the association between Indian Ocean sea-surface temperatures and summer rainfall over South Africa and Namibia, Int. J. Climatol., in press, 1999.

Lindesay, J. A., South Africa rainfall, the southern oscillation and a Southern Hemisphere semi-annual cycle, J. Climatol., 8, 17-30, 1988. 
Lindesay, J. A., and C. H. Vogel, Historical evidence for southern oscillation South African rainfall relationships, Int. J. Climatol., 10, 679-689, 1990.

Mason, S. J., and M. R. Jury, Climatic variability and change over southern Africa: A reflection on underlying processes, Progress Phys. Geog., 21, 23-50, 1997.

Mason, S. J., A. M. Joubert, C. Cosijn, and S. J. Crimp, Review of the current state of seasonal forecasting techniques with applicability to southern Africa, Water SA, 22, 203-209, 1996.

Mason, S. J., L. Goddard, N. E. Graham, E. Yulaeva, L. Sun, and P. A. Arkin, The IRI seasonal climate prediction system and the 1997/98 El Niño event, Bull. Am. Meteorol. Soc., in press, 1999.

Moura, A. D., and J. Shukla, On the dynamics of droughts in Northeast Brazil: Observations, theory, and numerical experiments with a general circulation model, J. Atmos. Sci., 38, 2536-2675, 1981.

Mutai, C. C., M. N. Ward, and A. W. Colman, Towards prediction of the east Africa short rains based on sea-surface temperature atmosphere coupling, Int. J. Climatol., 18, 975-997, 1998.

Nicholson, S., and D. Entekhabi, Rainfall variability in equatorial and southern Africa: Relationship with sea-surface temperature along the southwest coast of Africa, J. Appl. Meteorol. Clim., 26, 561-578, 1987.

Ogallo, L. J., Relationship between seasonal rainfall in east Africa and the southern oscillation, J. Climatol., 8, 31-43, 1988.

Ogallo, L. J., J. E. Janowaik, and M. S. Halpert, Teleconnection between seasonal rainfall over east Africa and global sea surface temperature anomalies, J. Meteorol. Soc. Jpn., 66, 807-821, 1989.

Pan, Y.-H., and A. H. Oort, Global climate variations connected with sea surface temperature anomalies in the eastern equatorial Pacific Ocean for the 1958-1973 period, Mon. Weather Rev., 111, 1244$1258,1983$.

Pathack, B., Modulation of South Africa rainfall by global climatic processes, Ph.D. thesis, Univ. of Cape Town, Cape Town, South Africa, 1993.

Rocha, A., and I. Simmonds, Interannual variability of southeastern African summer rainfall, I, Relationships with air-sea interaction processes, Int. J. Climatol., 17, 235-265, 1997a.

Rocha, A., and I. Simmonds, Interannual variability of southeastern African summer rainfall, II, Modelling the impact of sea-surface temperatures on rainfall and circulation, Int. J. Climatol., 17, 267$290,1997 \mathrm{~b}$.
Ropelewski, C. F., and M. S. Halpert, Global and regional scale precipitation patterns associated with the El Nin̄o/Southern Oscillation, Mon. Weather Rev., 115, 1606-1626, 1987.

Ropelewski, C. F., and M. S. Halpert, Precipitation patterns associated with the high index phase of the Southern Oscillation, J. Clim., 2, 268-284, 1989.

Smith, T. M., R. W. Reynolds, R. E. Livezey, and D. Stokes, Reconstruction of historical sea surface temperatures using empirical orthogonal functions, J. Clim., 9, 1403-1420, 1996.

Stockdale, T. N., D.L.T. Anderson, J.O.S. Alves, and M. A. Balmaseda, Global seasonal rainfall forecasts using a coupled oceanatmosphere model, Nature, 392, 370-373, 1998.

Stoeckenius, T., Interannual variations of tropical precipitation patterns, Mon. Weather Rev., 109, 1233-1247, 1981.

Tiedtke, M., A comprehensive mass flux scheme for cumulus parameterization in large-scale models, Mon. Weather Rev., 117, 1779$1800,1989$.

Tourre, Y. M., and W. B. White, Evolution of the ENSO signal over the Indo-Pacific domain, J. Phys. Oceanogr., 27, 683-696, 1997.

Tyson, P. D., Climate Change and Variability Over Southern Africa, Oxford Univ. Press, Cape Town, Cape Town, South Africa, 1986.

van Heerden, J., D. E. Terblanche, and G. C. Schulze, The Southern Oscillation and South African summer rainfall, J. Climatol., 8, 577$597,1988$.

Vose, R. S., R. L. Schmoyer, P. M. Steurer, T. C. Peterson, R. Heim, T. R. Karl, and J. K. Eischeid, The Global Historical Climatology Network: Long-term monthly temperature, precipitation, sea level pressure, and station pressure data, Tech. Rep. NDP-041, Carbon Dioxide Inf. Anal. Cent., Oak Ridge Natl. Lab., Oak Ridge, Tenn., 1992.

Webster, P. J., A. M. Moore, J. P. Loschnigg, and R. R. Leben, Coupled ocean-atmosphere instabilities in the Indian Ocean during 1997-1998, Nature, in press, 1999.

L. Goddard and N. E. Graham, International Research Institute for Climate Prediction, Experimental Forecast Division, Scripps Institution of Oceanography, MS 0235 La Jolla, CA 90293. (goddard@ lagoa.ucsd.edu)

(Received November 11, 1998; revised April 26, 1999; accepted May 7, 1999.) 